\title{
Meprin $\beta$ metalloproteases associated with differential metabolite profiles in the plasma and urine of mice with type 1 diabetes and diabetic nephropathy
}

Jessica Gooding ${ }^{1,2}$, Lei Cao ${ }^{3}$, Courtney Whitaker ${ }^{1,2}$, Jean-Marie Mwiza ${ }^{3}$, Mizpha Fernander ${ }^{3}$, Faihaa Ahmed ${ }^{3}$, Zach Acuff ${ }^{1,2}$, Susan McRitchie ${ }^{1,4}$, Susan Sumner ${ }^{1,4}$ and Elimelda Moige Ongeri ${ }^{3^{*}}$ (D)

\begin{abstract}
Background: Meprin metalloproteases are abundantly expressed in the brush border membranes of kidney proximal tubules and small intestines. Meprins are also expressed in podocytes and leukocytes (monocytes and macrophages). Meprins are implicated in the pathophysiology of diabetic nephropathy (DN) but underlying mechanisms are not fully understood. Single nucleotide polymophisms (SNPs) in the meprin $\beta$ gene were associated with DKD in human subjects. Furthermore, meprin a and $\beta$ double deficiency resulted in more severe kidney injury and higher mortality rates in mice with Streptozotocin (STZ)-induced type 1 diabetes. Identification of meprin substrates has provided insights on how meprins could modulate kidney injury. Meprin targets in the kidney include extracellular matrix (ECM) proteins, modulators of inflammation, and proteins involved in the protein kinase A (PKA) and PKC signaling pathways. The current study used a global metabolomics approach to determine how meprin $\beta$ expression impacts the metabolite milieu in diabetes and DKD.
\end{abstract}

Methods: Low dose STZ was used to induce type 1 diabetes in 8-week old wild-type (WT) and meprin $\beta$ knockout $(\beta K O)$ mice. Blood and urine samples were obtained at 4 and 8 weeks post-STZ injection. Assays for albumin, creatinine, neutrophil gelatinase-associated lipocalin (NGAL), kidney injury molecule -1 (KIM-1), and cystatin C were used for biochemical assessment of kidney injury. Data for biomarkers of kidney injury utilized two-way ANOVA. Metabolomics data analysis utilized UPLC-QTOF MS and multivariate statistics.

Results: The number of metabolites with diabetes-associated changes in levels were significantly higher in the WT mice when compared to meprin $\beta K O$ counterparts. Annotated meprin $\beta$ expression-associated metabolites with strong variable importance in projection (VIP) scores play roles in lipid metabolism (LysoPC(16:1(9Z)), taurocholic acid), amino acid metabolism (indoxyl sulfate, hippuric acid), and neurotransmitter/stress hormone synthesis (cortisol, 3-methoxy-4-hydroxyphenylethylene glycolsulfate, homovanillic acid sulfate). Metabolites that associated with meprin $\beta$ deficiency include; 3,5-dihydroxy-3',4'-dimethoxy-6,7-methylenedioxyflavone 3-glucuronide, pantothenic acid, and indoxyl glucuronide (all decreased in plasma).

Conclusion: Taken together, the annotated metabolites suggest that meprin $\beta$ impacts complications of diabetes such as DKD by altering distinct metabolite profiles.

Keywords: Meprin $\beta$ metalloprotease, Diabetic kidney injury, Metabolomics, Metabolites

\footnotetext{
*Correspondence: eongeri@ncat.edu

${ }^{3}$ Department of Biology, North Carolina A\&T State University, Greensboro, NC 27411, USA

Full list of author information is available at the end of the article
}

(c) The Author(s). 2019 Open Access This article is distributed under the terms of the Creative Commons Attribution 4.0 International License (http://creativecommons.org/licenses/by/4.0/), which permits unrestricted use, distribution, and reproduction in any medium, provided you give appropriate credit to the original author(s) and the source, provide a link to the Creative Commons license, and indicate if changes were made. The Creative Commons Public Domain Dedication waiver (http://creativecommons.org/publicdomain/zero/1.0/) applies to the data made available in this article, unless otherwise stated. 


\section{Background}

Diabetes is the leading cause of chronic kidney disease (CKD) with $20-40 \%$ of patients with type 2 diabetes (T2D) developing diabetic nephropathy (DN). For patients at risk for progressing to $\mathrm{DN}$, early diagnosis and targeted interventions are hindered by the lack of sensitive and accurate tools for early diagnosis. This is in part because the underlying cellular and molecular mechanisms are not fully understood. Meprins are zinc metalloproteases of the astacin family and are most abundantly expressed in the brush border membranes (BBM) of proximal kidney tubules and small intestines $[1,2]$. Meprins are also expressed in podocytes [3], and leukocytes (monocytes and macrophages) [4]. Meprins are composed of $\alpha$ and $\beta$ subunits, that are encoded by distinct genes, resulting in two highly similar protein isoforms [5, 6]. Meprin A is a homooligomer of $\alpha$ subunits $(\alpha-\alpha)$ or a heterodimer of $\alpha$ and $\beta$ subunits $(\alpha-\beta)$, while meprin $B$ is a homooligomer of $\beta$ subunits $(\beta-\beta)$ [7]. Meprins have been implicated in the pathology of $\mathrm{DN}$ in human patients and in mouse models of DN [811]. Meprin $\beta$ gene single nucleotide polymorphisms (SNPs) were associated with DN and end stage renal disease (ESRD) in the Pima Indians, a Native American ethnic group with extremely high incidences of type 2 diabetes and ESRD [9]. Both meprin $\alpha$ and meprin $\beta$ gene and protein expression levels were down-regulated in the kidneys of diabetic rats, and $\mathrm{db} / \mathrm{db}$ mice before development of overt kidney disease. In mice with streptozotocin (STZ)-induced type 1 diabetes, meprin $\alpha$ and meprin $\beta$ double deficiency resulted in a more severe form of kidney injury [12], suggesting that meprins protect against DN. Glomerular meprin expression has also been documented in rats with glomerulonephritis [3] and mice with DN [13]. However, the mechanism(s) by which meprins modulate diabetic kidney injury are not fully understood. Several studies have contributed to knowledge on potential mechanisms via identification of meprin targets present in the kidney [14-29], The levels of urinary meprins and two meprin targets (nidogen-1 and $\mathrm{MCP}-1$ ) positively correlated with the severity of kidney injury in diabetic African American men [30]. Many of the known meprin targets also play a role in the pathology of DN (e.g. inflammation and fibrosis). However, the metabolic pathways impacted by proteolytic processing of meprin targets are not known. This knowledge is important in understanding how meprins modulate diabetic kidney injury and in development of new diagnostic and therapeutic targets. Metabolomics tools have shown great promise in development of diagnostic and prognostic biomarkers as well as in advancing our understanding of the molecular mechanisms underlying the pathology of CKD [31-38]. In a metabolome-wide association study, kidney function-associated metabolites were shown to have potential as filtration markers which could serve for assessment of kidney function [33]. Experiments with non-obese diabetic mice showed differences in the plasma metabolites of mice which progressed to type 1 diabetes when compared to non-diabetic counterparts [39]. Metabolomics profiling of serum, urine, and renal extracts from rats with DN also identified several DN-related metabolites which included higher levels of allantoin and uric acid [32]. The objective of the current study was to use meprin $\beta$ knockout mice (in which the meprin $\beta$ gene is disrupted) and global metabolomics analysis to gain understanding of the mechanisms by which meprin $\beta$ modulate kidney injury by identifying meprin $\beta$-associated changes in plasma and urine metabolites.

\section{Methods}

Experimental animals

Wild-type (WT) and meprin $\beta$ knockout $(\beta \mathrm{KO})$ male mice on a C57BL/6 background were used for these studies. The meprin $\beta K O$ mice were generated by the laboratory of Dr. Judith S. Bond at Pennsylvania State University College of Medicine in Hershey Pennsylvania and bred to obtain experimental mice which were housed at the Laboratory Animal Resource Unit (LARU) of North Carolina A\&T State University. The WT mice were purchased from Charles River Laboratories at age 6 weeks and subsequently housed at LARU. The mice were housed in group cages (up to 5 mice per cage), maintained on a 12:12 h light:dark cycle, and provided rat chow and water ad libitum. The protocols used were reviewed and approved by the North Carolina A\&T State University Institutional Animal Care and Use Committee (IACUC). The WT mice express both meprin $A(\alpha-\alpha$ and $\alpha-\beta)$ and meprin $B(\beta-\beta)$ protein isoforms while the meprin $\beta$ KO mice only express homomeric meprin A $(\alpha-\alpha)$ and are deficient in meprin B $(\beta-\beta)$ and the heterodimeric form of meprin $A(\alpha-\beta)$. The meprin $\beta$ KO mice have no obvious phenotype under normal physiology but demonstrate key differences under renal pathological conditions. For each genotype, the mice were randomly allocated to two treatment groups, STZ $(n=10)$ or sodium citrate $(\mathrm{NaC})$ $(n=6)$.

\section{Induction of diabetes}

Type 1 diabetes was induced at age 8 weeks by intraperitoneal injection of low dose STZ ( $50 \mathrm{mg} / \mathrm{kg}$ body weight) in $10 \mathrm{mM} \mathrm{NaC}$ buffer ( $\mathrm{pH} 4.5$ ) daily for 5 consecutive days following the protocol described by Tesch and Allen (2007) [40], and recommended by the Animal Models of Diabetic Complications Consortium (AMDCC). Control mice were injected with $\mathrm{NaC}$ buffer vehicle. Diabetes was confirmed by determining fasting blood glucose levels using a glucose meter at 10 days 
post-STZ injection. Mice with fasting glucose levels $\geq 280 \mathrm{mg} / \mathrm{dL}$ were considered diabetic. STZ-injected mice with fasting blood glucose levels $<280 \mathrm{mg} / \mathrm{dL}$ ( $n=$ $1 \mathrm{WT}$ and $n=2 \beta \mathrm{KO}$ ) were culled and eliminated from the study. The body weights were monitored on a weekly basis.

\section{Collection of urine and blood}

Blood and urine samples were collected at 4 and 8 weeks post-STZ injection. Blood was obtained by tail nicking at week 4 and by cardiac puncture at week 8 when the mice were sacrificed. The blood samples were collected into heparinized tubes, centrifuged to obtain plasma, and stored at $-80^{\circ} \mathrm{C}$ until used. Urine samples were obtained by bladder massage into sterile petri dishes and stored at $-80^{\circ} \mathrm{C}$ until used. The mice were sacrificed at week 8 by $\mathrm{CO}_{2}$ asphyxiations.

\section{Biochemical assessment for kidney injury}

To confirm kidney injury, we performed assays for biomarkers of kidney injury, namely; urinary albumin and creatinine, plasma neutrophil gelatinase-associated lipocalin (NGAL), kidney injury molecule-1 (KIM-1), and cystatin $\mathrm{C}$. The assays for creatinine utilized a colorimetric based enzymatic assay kit (Diazyme Laboratories, Poway CA) while assays for albumin, NGAL, KIM-1, and cystatin $\mathrm{C}$ utilized quantitative sandwich enzyme immunoassay kits (Exocell, Philadelphia, PA for albumin and R\&D Systems, Minneapolis, MN for the rest). The assays were performed according to the manufacturers' instructions. The samples were run in duplicate and the optical density (OD) read using a M200 Pro multimode plate reader (Tecan, USA). For NGAL, KIM-1 and cystatin $C$, the standard curves were plotted using a 4-parameter logistic curve fit (4-PL) using GraphPad Prism 7.0 Software. The ELISA data were analyzed by 2-way ANOVA with multiple comparisons. $P$ values $\leq 0.05$ were considered significant. For the fold-change in urinary KIM-1 the levels for non-diabetic $\mathrm{NaC}$ treated mice were used as the reference point.

\section{Sample preparation for metabolomics analysis}

Urine samples were thawed, vortexed and centrifuged at $16,000 \times \mathrm{g}$ for $4 \mathrm{~min}$. The supernatant $(40 \mu \mathrm{L})$ was transferred to a low protein-binding microcentrifuge tube for each individual, quality control (QC), equilibration (EQ), and total study pool sample. The internal standard working solution $(120 \mu \mathrm{L} ; 0.0167 \mathrm{mg} / \mathrm{mL}$ Tryptophan-d5 in acetonitrile) was added to all samples, and samples were mixed for $2 \mathrm{~min}$ at $5000 \mathrm{rpm}$ then centrifuged at $16,000 \times \mathrm{g}$ for $4 \mathrm{~min}$. Samples were stored at $-20^{\circ} \mathrm{C}$ until the day of analysis. Samples were vortex mixed for $2 \mathrm{~min}$ at $5000 \mathrm{rpm}$, centrifuged at $16,000 \times \mathrm{g}$ for $4 \mathrm{~min}$, and the supernatants were transferred to glass autosampler vials for injection on the UPLC-QTOF MS system.

Plasma samples were thawed for $30-60 \mathrm{~min}$ on ice, followed by mixing at $5000 \mathrm{rpm}$ for $4 \mathrm{~min}$ on a multiple-tube vortex mixer and centrifugation at $16,000 \times \mathrm{g}$ for $4 \mathrm{~min}$. The plasma supernatants $(40 \mu \mathrm{L})$ were transferred to a low protein-binding microcentrifuge tube for each individual, QC, EQ, and total study pool sample. The internal standard working solution $(320 \mu \mathrm{L} ; 0.0125 \mathrm{mg} / \mathrm{mL}$ Tryptophan-d5 in methanol) was added to all samples and were vortexed at $5000 \mathrm{rpm}$ for $2 \mathrm{~min}$ then centrifuged at $16,000 \times \mathrm{g}$ for $4 \mathrm{~min}$. Supernatants $(290 \mu \mathrm{L})$ were transferred to fresh low protein-binding microcentrifuge tubes and capped with rubber stoppers. Tubes were stored at $-80^{\circ} \mathrm{C}$ for $1 \mathrm{~h}$ prior to lyophilization to complete dryness for $18 \mathrm{~h}$. Samples were stored at $-80^{\circ} \mathrm{C}$ for 5 days. On the day of analysis, samples were reconstituted in 95:5 acetonitrile:water $(125 \mu \mathrm{L})$, mixed at $5000 \mathrm{rpm}$ for $10 \mathrm{~min}$, centrifuged at $16,000 \times \mathrm{g}$ for $4 \mathrm{~min}$, and the supernatants were transferred to glass autosampler vials for injection on the UPLC-QTOF MS system.

\section{Metabolomics quality control}

All samples were prepared and analyzed in a randomized order. $11 \mu \mathrm{L}$ of urine or plasma from all individual study samples were transferred to one, low protein-binding microcentrifuge tube to create the total pool. These total pools were vortex mixed for $30 \mathrm{~s}$ and aliquoted to create QC and column EQ samples. Equilibration samples were injected multiple times at the beginning of the analysis to ensure column equilibration. QC samples were evenly distributed throughout the analytical run every 7-10 samples and used to evaluate technical reproducibility of the data and monitor analytical drift. In addition, a volume of the urine $(132 \mu \mathrm{L})$, plasma $(132 \mu \mathrm{L})$, and kidney homogenate $(132 \mu \mathrm{L}$, data not reported here) total pools were mixed to create a total study pool to aid in data alignment and comparison across the three matrices. The total study pool was used to prepare 9 total study pool samples, and 3 total study pool samples were included in each analysis. The mass spectrometer was calibrated at the beginning of each analytical run, and a leucine enkephalin reference was introduced throughout for lock mass correction during data analysis steps. A mixture of standards was injected at the beginning and the end of the run to evaluate system suitability and instrument drift.

\section{HILIC UPLC-QTOF MS analysis}

A hydrophilic interaction liquid chromatography (HILIC) broad spectrum metabolomics method was used to detect metabolites. Samples were analyzed by ultra performance liquid chromatography-quadrupole time-of 
flight mass spectrometry (UPLC-QTOF MS) using an Acquity I-class connected to a Synapt G2-Si system (Waters, Milford, MA, USA). The UPLC-QTOF MS system was directed by MassLynx 4.1 software to inject and analyze the samples. A volume of $3 \mu \mathrm{L}$ of each sample was carried by a two solvent system (mobile phase A: 10 $\mathrm{mM}$ ammonium acetate in 95:5 acetonitrile: $\mathrm{H}_{2} \mathrm{O}$ with $0.1 \%$ Formic Acid and mobile phase B: $10 \mathrm{mM}$ ammonium acetate in 50:50 acetonitrile: $\mathrm{H}_{2} \mathrm{O}$ with $0.1 \%$ Formic Acid) with a flow rate of $0.400 \mathrm{~mL} / \mathrm{min}$ to the Acquity UPLC BEH Amide column $(2.1 \mathrm{X} 100 \mathrm{~mm} 1.7 \mu \mathrm{m})$. The column temperature was set to $40^{\circ} \mathrm{C}$ and the gradient was as follows: $\mathrm{t}=0 \mathrm{~min}, 1 \% \mathrm{~B} ; \mathrm{t}=1 \mathrm{~min}, 1 \% \mathrm{~B} ; \mathrm{t}=12$ $\min , 50 \% \mathrm{~B} ; \mathrm{t}=14 \min , 50 \% \mathrm{~B} ; \mathrm{t}=15 \mathrm{~min}, 1 \% \mathrm{~B} ; \mathrm{t}=19$ min, $1 \%$ B. A mixture of standards was first injected to check the system suitability, and the column was equilibrated with repeat injections of EQ samples immediately prior to injection of the study samples (individual and QC samples). After separation on the column, samples were directed towards the Synapt G2Si ESI-Q-TOF instrument to be analyzed in positive and negative modes. ESI source settings were as follows: capillary voltage 1.0 $\mathrm{kV}$; sampling cone 40; source offset 80 ; source temperature $110{ }^{\circ} \mathrm{C}$; desolvation temperature $400{ }^{\circ} \mathrm{C}$; cone gas $50 \mathrm{~L} / \mathrm{h}$; desolvation gas $1000 \mathrm{~L} / \mathrm{h}$; nebulizer 6.5 bar; lock spray capillary $1.0 \mathrm{kV}$ and lockspray flow rate 3 $\mathrm{L} / \mathrm{min}$. Ions were analyzed in MSE continuum mode with trap collision energy ramping from 20 to $30 \mathrm{~V}$ for the high energy scan. The scan range was set to 50 $1000 \mathrm{~m} / \mathrm{z}$ with a scanning cycle of $0.6 \mathrm{~s}$ in resolution mode (resolution approx. 18,000).

\section{Metabolomics data analysis}

Progenesis QI software (Nonlinear Dynamics, UK) was used to align, pick peaks, deconvolute and annotate compounds. One negative mode sample, a STZ-treated WT 8 week plasma, was removed due to large deviations in total ion intensity. The lock-mass signal was unstable in several samples which created problems with data alignment in the mass dimension and outliers in the multivariate analysis, which led to the exclusion of one sample, a plasma pool, in positive mode and three STZ-treated 4 week plasma samples, two WT and one $\beta K O$, in negative mode. The criteria for selecting compounds for further analysis was as follows: retention time greater than $1 \mathrm{~min}$, peak width between 0.1 and 2 min, an abundance greater than 200 in at least 4 of 5 pooled QC samples, and a CV less than 0.4 amongst QC samples when normalized by the total intensity of all compounds picked by the automatic algorithm. The sum of intensities of this compound subset was subsequently used to normalize the intensities of all samples in the matrix before Pareto scaling and multivariate analysis. This is in line with previous approaches for normalization of metabolites in urine samples [41-44]. Unsupervised multivariate analysis (principle components analysis, PCA) was performed using SIMCA 14.1 (Umetrics, Umeå, Sweden) to evaluate data structure and supervised multivariate analysis (orthogonal partial least squares - discriminant analysis, OPLS-DA) was used to determine important group differentiating metabolites. Univariate statistics completed in SAS 9.4 (SAS Institute Inc., Cary, NC, USA). Hypotheses were tested with Exact Wilcoxon Rank Sum or Wilcoxon Rank Sum tests as indicated in Tables 1, 2, 3, 4 and 5. Compounds with a variable importance in projection (VIP) score $>2$ in at least one OPLS-DA group comparison were prioritized for identification and interpretation. The HMDB database (www.hmdb.ca) was searched by exact mass in Progenesis QI to annotate compounds. The mass error $(<10 \mathrm{ppm})$, isotope similarity $(>70 \%)$, match between in silico fragmentation results and fragments in high energy spectra (at least one fragment $<12$ ppm mass error, not the loss of water) and potential biological relevance were evaluated for passing tolerances before reporting annotated compounds. Compounds referred to as "differentiating" or having "changed levels" throughout the text and included in the tables have VIP $\geq 2$ where the jackknifed confidence interval does not include 0 or $p$-value $<0.05$.

All raw and processed analytical data and associated metadata have been deposited into the $\mathrm{NIH}$ Common Fund's Data Repository and Coordinating Center (supported by NIH grant, U01-DK097430) website, http:// www/metabolomicsworkbench.org, where it has been assigned Metabolomics Workbench Project IDs PR000409 (plasma) and PR000410 (urine). The data is directly accessible at the following websites: http://www. metabolomicsworkbench.org/data/DRCCMetadata. php?Mode=Project\&ProjectID=PR000409OR https://bit. ly/2C95oe1

http://www.metabolomicsworkbench.org/data/ DRCCMetadata.php? Mode=Project\&ProjectID $=$ PR000410OR https://bit.ly/2tUReZK

\section{Results \\ Meprin $\beta$ expression is associated with higher levels of kidney injury}

Overall, WT mice with STZ-induced type 1 diabetes had higher levels of kidney injury when compared to meprin $\beta K O$ mice. The urinary albumin to creatinine ratios (UACR) were significantly higher for WT mice at both 4 $(p=0.0042)$ and 8 weeks $(p=0.0383)$ post-STZ injection. In contrast, meprin $\beta K O$ mice had a modest increase in UACR at 8 weeks post-STZ (Fig. 1, panel A). The ratio of urinary KIM-1 to creatinine showed significant increases in both WT and meprin $\beta K O$ mice at 4 and 8 weeks post-STZ but the baseline levels were higher in 
Table 1 PCA/multivariate Analysis models for plasma

\begin{tabular}{|c|c|c|c|c|c|c|c|c|c|}
\hline & Model & $\begin{array}{l}\text { \# of } \\
\text { Compounds }\end{array}$ & $\begin{array}{l}\text { Total \# } \\
\text { Samples }\end{array}$ & $\begin{array}{l}\text { \# of } \\
\text { Components }\end{array}$ & R2X & R2Y & Q2 & $\begin{array}{l}\text { \# Samples in } \\
\text { STZ }\end{array}$ & $\begin{array}{l}\text { \# Samples in } \\
\mathrm{NaC}\end{array}$ \\
\hline \multirow[t]{11}{*}{ Positive } & PCA All Samples & 2414 & 62 & 7 & 0.947 & & 0.85 & & \\
\hline & PCA 4 wks & 2414 & 28 & 7 & 0.96 & & 0.841 & & \\
\hline & PCA WT STZ v WT NaC 4 wk & 2414 & 14 & 4 & 0.937 & & 0.759 & & \\
\hline & $\begin{array}{l}\text { OPLSDA WT STZ v WT NaC } 4 \\
\text { wk }\end{array}$ & 2414 & 14 & $1+1$ & 0.75 & 0.619 & 0.0699 & 9 & 5 \\
\hline & PCA $\beta K O S T Z \vee \beta K O ~ N a C ~ 4 w k$ & 2414 & 14 & 4 & 0.93 & & 0.756 & & \\
\hline & $\begin{array}{l}\text { OPLSDA } \beta K O S T Z \vee \beta K O ~ N a C \\
4 w k\end{array}$ & 2414 & 14 & $1+3$ & 0.908 & 0.956 & 0.788 & 8 & 6 \\
\hline & PCA 8 wks & 2414 & 28 & 5 & 0.942 & & 0.834 & & \\
\hline & PCA WT STZ v WT NaC 8 wk & 2414 & 13 & 5 & 0.967 & & 0.829 & & \\
\hline & $\begin{array}{l}\text { OPLSDA WT STZ v WT NaC } 8 \\
\text { wk }\end{array}$ & 2414 & 13 & $1+2$ & 0.845 & 0.912 & 0.764 & 8 & 5 \\
\hline & PCA $\beta K O ~ S T Z \vee \beta K O ~ N a C ~ 8 w k$ & 2414 & 14 & 4 & 0.962 & & 0.912 & & \\
\hline & $\begin{array}{l}\text { OPLSDA } \beta K O S T Z \vee \beta K O ~ N a C \\
8 w k\end{array}$ & 2414 & 14 & $1+7$ & 0.984 & 1 & 0.731 & 8 & 6 \\
\hline \multirow[t]{11}{*}{ Negative } & PCA All Samples & 633 & 57 & 8 & 0.877 & & 0.711 & & \\
\hline & PCA 4 wks & 633 & 25 & 3 & 0.76 & & 0.385 & & \\
\hline & PCA WT STZ v WT NaC 4 wk & 633 & 12 & 4 & 0.925 & & 0.558 & & \\
\hline & $\begin{array}{l}\text { OPLSDA WT STZ v WT NaC } 4 \\
\text { wk }\end{array}$ & 633 & 12 & $1+2$ & 0.873 & 0.962 & 0.876 & 7 & 5 \\
\hline & PCA $\beta K O S T Z \vee \beta K O ~ N a C ~ 4 w k$ & 633 & 13 & 2 & 0.58 & & 0.23 & & \\
\hline & $\begin{array}{l}\text { OPLSDA } \beta K O S T Z \vee \beta K O ~ N a C \\
4 w k\end{array}$ & 633 & 13 & $1+1$ & 0.528 & 0.958 & 0.876 & 7 & 6 \\
\hline & PCA 8 wk & 633 & 26 & 3 & 0.759 & & 0.478 & & \\
\hline & PCA WT STZ v WT NaC 8 wk & 633 & 12 & 3 & 0.866 & & 0.497 & & \\
\hline & $\begin{array}{l}\text { OPLSDA WT STZ v WT NaC } 8 \\
\text { wk }\end{array}$ & 633 & 12 & $1+2$ & 0.861 & 0.973 & 0.907 & 7 & 5 \\
\hline & PCA $\beta K O ~ S T Z \vee \beta K O ~ N a C ~ 8 w k$ & 633 & 14 & 3 & 0.759 & & 0.174 & & \\
\hline & $\begin{array}{l}\text { OPLSDA } \beta K O S T Z \vee \beta K O ~ N a C \\
8 w K\end{array}$ & 633 & 14 & $1+1$ & 0.498 & 0.871 & 0.686 & 8 & 6 \\
\hline
\end{tabular}

WT mice when compared to meprin $\beta K O$ counterparts (Fig. 1, panel B). There were no significant differences between the two genotypes in the fold-change of the urinary KIM-1/Creatinine ratios at either 4 or 8 weeks (Fig. 1, panel C). The ratios of urinary NGAL to creatinine were also significantly higher at 4 weeks in diabetic WT mice when compared to diabetic meprin $\beta K O$ counterparts (Fig. 2, panel A). In contrast, there were no significant changes in plasma NGAL for either genotype at 4 or 8 weeks post-STZ injection (Fig. 2, panel B). While plasma cystatin $\mathrm{C}$ levels decreased in WT mice at 4 weeks post-STZ, the decrease was not sustained at 8 weeks post STZ and was not observed in the meprin $\beta K O$ mice (Fig. 2, panel D). Furthermore, there were no significant differences in the urinary cystatin $\mathrm{C}$ levels (Fig. 2, panel C) even though there was a modest increase in WT mice which also showed great individual variations.
Meprin expression alters plasma and urinary metabolite profiles in mice with STZ-induced type 1 diabetes

Our data show distinct changes in the profiles of metabolites present in plasma and urine associated with STZ-induced type 1 diabetes and diabetic kidney injury in WT and meprin $\beta K O$ mice. The PCA score plot for all plasma samples in positive mode showed duration of diabetes status was the major source of variability (Fig. 3 panel A; $R^{2} X($ cum $)=0.947 ; Q^{2}$ (cum $\left.)=0.85\right)$. In contrast, the overall PCA of urine and plasma negative mode datasets indicated that the strongest source of variability was due to diabetes status (Fig. 3 panel A and Fig. 4 panel A; Model fit statistics (Tables 1 and 2). QC samples were tightly clustered, and near the center of the datasets, demonstrating technical reproducibility of the data. When compared to plasma, the number of differentiating metabolites in urine were much higher for both genotypes reflecting the control over homeostasis in 
Table 2 PCA/multivariate Analysis models for urine

\begin{tabular}{|c|c|c|c|c|c|c|c|c|c|}
\hline & Model & $\begin{array}{l}\text { \# of } \\
\text { Compounds }\end{array}$ & $\begin{array}{l}\text { Total \# } \\
\text { Samples }\end{array}$ & $\begin{array}{l}\text { \# of } \\
\text { Components }\end{array}$ & R2X & R2Y & Q2 & $\begin{array}{l}\text { \# Samples in } \\
\text { STZ }\end{array}$ & $\begin{array}{l}\text { \# Samples in } \\
\mathrm{NaC}\end{array}$ \\
\hline \multirow[t]{11}{*}{ Positive } & PCA All Samples & 3513 & 54 & 5 & 0.781 & & 0.663 & & \\
\hline & PCA 4 wks & 3513 & 24 & 2 & 0.711 & & 0.627 & & \\
\hline & PCA WT STZ v WT NaC 4 wk & 3513 & 13 & 2 & 0.783 & & 0.676 & & \\
\hline & $\begin{array}{l}\text { OPLSDA WT STZ v WT NaC } 4 \\
\text { wk }\end{array}$ & 3513 & 13 & $1+1$ & 0.775 & 0.993 & 0.981 & 9 & 4 \\
\hline & PCA $\beta K O S T Z \vee \beta K O ~ N a C ~ 4 w k$ & 3513 & 11 & 2 & 0.770 & & 0.634 & & \\
\hline & $\begin{array}{l}\text { OPLSDA } \beta K O S T Z \vee \beta K O ~ N a C \\
4 w k\end{array}$ & 3513 & 11 & $1+0$ & 0.598 & 0.596 & 0.444 & 8 & 3 \\
\hline & PCA 8 wks & 3513 & 24 & 4 & 0.803 & & 0.641 & & \\
\hline & PCA WT STZ v WT NaC 8 wk & 3513 & 13 & 2 & 0.774 & & 0.648 & & \\
\hline & $\begin{array}{l}\text { OPLSDA WT STZ v WT NaC } 8 \\
\text { wk }\end{array}$ & 3513 & 13 & $1+1$ & 0.642 & 0.937 & 0.916 & 8 & 5 \\
\hline & PCA $\beta K O ~ S T Z \vee \beta K O ~ N a C ~ 8 w k$ & 3513 & 11 & 3 & 0.839 & & 0.546 & & \\
\hline & $\begin{array}{l}\text { OPLSDA } \beta K O S T Z \vee \beta K O ~ N a C \\
8 w k\end{array}$ & 3513 & 11 & $1+4$ & 0.893 & 0.999 & 0.841 & 6 & 5 \\
\hline \multirow[t]{11}{*}{ Negative } & PCA All Samples & 4116 & 53 & 8 & 0.753 & & 0.486 & & \\
\hline & PCA 4 wks & 4116 & 24 & 4 & 0.692 & & 0.477 & & \\
\hline & PCA WT STZ v WT NaC 4 wk & 4116 & 13 & 2 & 0.632 & & 0.453 & & \\
\hline & $\begin{array}{l}\text { OPLSDA WT STZ v WT NaC } 4 \\
\text { wk }\end{array}$ & 4116 & 13 & $1+3$ & 0.73 & 1 & 0.983 & 9 & 4 \\
\hline & PCA $\beta K O S T Z \vee \beta K O ~ N a C ~ 4 w k$ & 4116 & 11 & 2 & 0.566 & & 0.254 & & \\
\hline & $\begin{array}{l}\text { OPLSDA } \beta K O S T Z \vee \beta K O ~ N a C \\
4 w K\end{array}$ & 4116 & 11 & $1+0$ & 0.333 & 0.644 & 0.451 & 8 & 3 \\
\hline & PCA 8 wk & 4116 & 24 & 4 & 0.646 & & 0.327 & & \\
\hline & PCA WT STZ v WT NaC 8 wk & 4116 & 13 & 4 & 0.767 & & 0.311 & & \\
\hline & $\begin{array}{l}\text { OPLSDA WT STZ v WT NaC } 8 \\
\text { wk }\end{array}$ & 4116 & 13 & $1+0$ & 0.409 & 0.953 & 0.921 & 8 & 5 \\
\hline & PCA $\beta K O S T Z \vee \beta K O ~ N a C ~ 8 w k$ & 4116 & 11 & 2 & 0.574 & & 0.174 & & \\
\hline & $\begin{array}{l}\text { OPLSDA } \beta K O S T Z \vee \beta K O ~ N a C \\
8 w k\end{array}$ & 4116 & 11 & $1+6$ & 0.894 & 1 & 0.816 & 6 & 5 \\
\hline
\end{tabular}

plasma (Table 3 and Additional file 1: Tables S1, S2, S3,S4, S5, S6, S7 and S8). Similarly, separation by treatment type was more pronounced in urine in the PCA for most models. In addition to meprin-associated changes in metabolite levels (Tables 4 and 6), several metabolites differentiated diabetic from non-diabetic controls in both WT and meprin $\beta K O$ mice (Tables 5 and 7), suggesting an association with diabetic status but independent on meprin expression/activity or deficiency. For both genotypes, there were more differentiating

Table 3 Total numbers of differentiating metabolites in the positive and negative modes at 4 and 8 weeks post-STZ

\begin{tabular}{|c|c|c|c|c|c|c|c|c|c|c|c|}
\hline & & \multicolumn{5}{|c|}{4 Weeks post STZ } & \multicolumn{5}{|c|}{8 weeks post-STZ } \\
\hline & & \multicolumn{2}{|c|}{ Positive Mode } & \multicolumn{2}{|c|}{ Negative Mode } & \multirow[t]{2}{*}{ Total } & \multicolumn{2}{|c|}{ Positive Mode } & \multicolumn{2}{|c|}{ Negative Mode } & \multirow[t]{2}{*}{ Total } \\
\hline & & Unknown & annotated & Unknown & annotated & & Unknown & annotated & Unknown & annotated & \\
\hline \multirow[t]{3}{*}{ Plasma } & BKO Only & 118 & 4 & 71 & 5 & 198 & 69 & 0 & 77 & 1 & 147 \\
\hline & WT only & 47 & 2 & 105 & 5 & 159 & 236 & 9 & 122 & 7 & 374 \\
\hline & Both $W T$ and $\beta K O$ & 52 & 4 & 108 & 7 & 171 & 85 & 5 & 113 & 7 & 210 \\
\hline \multirow[t]{3}{*}{ Urine } & $\beta K O$ Only & 7 & 1 & 14 & 2 & 24 & 120 & 9 & 244 & 14 & 387 \\
\hline & WT only & 2475 & 30 & 2330 & 39 & 4874 & 1761 & 22 & 1636 & 18 & 3437 \\
\hline & Both $W T$ and $\beta K O$ & 95 & 13 & 98 & 20 & 226 & 641 & 21 & 674 & 32 & 1368 \\
\hline
\end{tabular}


Table 4 Summary of differentiating plasma metabolites at 4- and 8-weeks post STZ with a $2 \leq$ FC and/or $2 \leq$ VIP. A variable importance in projection (VIP) score $2 \leq$ are considered to have strong predictive value. Meprin expression associated metabolites (in either WT or meprin $\beta K O$ mice only)

\begin{tabular}{|c|c|c|c|c|c|c|c|c|}
\hline & \multicolumn{4}{|l|}{4 Weeks post STZ } & \multicolumn{4}{|l|}{8 weeks Post STX } \\
\hline & Metabolite & VIP & $P$-value* & $\mathrm{FC}^{* *}$ & Metabolite & VIP & $P$-value* & $\mathrm{FC}^{* *}$ \\
\hline \multirow[t]{13}{*}{ WT Only } & $\begin{array}{l}\text { 3-Methoxy-4-hydroxyphenylethyleneglycol } \\
\text { sulfate }\end{array}$ & 0.7 & 0.003 & 6.6 & $\begin{array}{l}\text { 3-Methoxy-4-hydroxyphenylethyleneglycol } \\
\text { sulfate }\end{array}$ & 0.5 & 0.01 & 9.1 \\
\hline & N-Heptanoylglycine & 0.6 & 0.005 & -5.2 & 3-Aminosalicylic acid & 0.9 & 0.045 & 3.6 \\
\hline & 3-Methoxytyrosine & 0.5 & 0.018 & -3.8 & LysoPC(16:1(9Z)) & 3 & 0.019 & -3.6 \\
\hline & 7-Methoxy-5-prenyloxycoumarin & 0.6 & 0.042 & 2 & 5-Acetyl-2,4-dimethyloxazole & 0.4 & 0.003 & 3.1 \\
\hline & & & & & Guanine & 0.3 & 0.019 & 2.7 \\
\hline & & & & & Taurocholic acid & 3.2 & 0.019 & 2.5 \\
\hline & & & & & 9'-Carboxy-gamma-chromanol & 0.5 & 0.019 & 2.5 \\
\hline & & & & & Riboflavin & 0.4 & 0.019 & 2.5 \\
\hline & & & & & N-Acetylleucine & 1 & 0.005 & 2.2 \\
\hline & & & & & Indoxyl sulfate & 5.3 & 0.003 & 2.1 \\
\hline & & & & & 2-Phenylglycine & 0.3 & 0.003 & 2.1 \\
\hline & & & & & N-Heptanoylglycine & 0.2 & 0.03 & -2.1 \\
\hline & & & & & 7-Methoxy-5-prenyloxycoumarin & 0.4 & 0.019 & 2 \\
\hline \multirow{7}{*}{$\begin{array}{l}\text { BKO } \\
\text { Only }\end{array}$} & Porric acid B & 0.5 & 0.021 & 3.7 & \multirow[t]{7}{*}{ Isovalerylalanine } & \multirow[t]{7}{*}{0.7} & \multirow[t]{7}{*}{0.016} & \multirow[t]{7}{*}{-2.5} \\
\hline & $\begin{array}{l}\text { 3-Methoxy-4-hydroxyphenylethyleneglycol } \\
\text { sulfate }\end{array}$ & 1.7 & 0.047 & 3.3 & & & & \\
\hline & L-Acetylcarnitine & 1 & 0.021 & 3.1 & & & & \\
\hline & D-1,5-Anhydrofructose & 0.8 & 0.01 & -3.1 & & & & \\
\hline & Hexanoylcarnitine & 0.5 & 0.042 & -2.2 & & & & \\
\hline & N-Acetylleucine & 1 & 0.021 & 2 & & & & \\
\hline & Tyrosyl-Valine & 0.3 & 0.016 & 2 & & & & \\
\hline
\end{tabular}

$p$-value* $: p$-value for Exact Wilcoxon Rank Sum Test

$F^{* *}$ : A positive or negative fold change indicates median of STZ $>$ median of $\mathrm{NaC}$

Table 5 Summary of differentiating plasma metabolites at 4- and 8-weeks post STZ with a $2 \leq$ FC and/or $2 \leq$ VIP. A variable importance in projection (VIP) score $2 \leq$ are considered to have strong predictive value. Diabetes/STZ associated plasma metabolites independent of meprin $\beta$ expression/deficiency (change in both WT and meprin $\beta K O$ mice)

\begin{tabular}{|c|c|c|c|c|c|c|c|c|c|c|c|c|c|}
\hline \multicolumn{7}{|l|}{4 Weeks post STZ } & \multicolumn{7}{|l|}{8 weeks post-STZ } \\
\hline & \multicolumn{3}{|l|}{ WT } & \multicolumn{3}{|c|}{$\beta K O$} & & \multicolumn{3}{|l|}{ WT } & \multicolumn{3}{|c|}{$\beta K O$} \\
\hline & VIP & $P$-value* & $\mathrm{FC}^{* *}$ & VIP & $P$-value & $\mathrm{FC}^{* *}$ & & VIP & $P$-value* & $\mathrm{FC}^{* *}$ & VIP & $P$-value* & $\mathrm{FC}^{* *}$ \\
\hline Cortisol & 1.7 & 0.003 & 23.2 & 0.9 & 0.013 & 2.4 & Indole-3-carboxilic acid-O-sulphate & 0.5 & 0.003 & 6.2 & 0.1 & 0.01 & 935.1 \\
\hline $\begin{array}{l}\text { Indole-3-carboxilic acid-O- } \\
\text { sulphate }\end{array}$ & 0.7 & 0.005 & 4.7 & 0.2 & 0.013 & 10.3 & Equol 7-O-glucuronide & 0.3 & 0.002 & 4.5 & 0.4 & 0.02 & 3.2 \\
\hline LysoPC(16:1(9Z)) & 5.1 & 0.002 & -4 & 4.8 & 0.026 & -2.3 & Cortisol & 0.9 & 0.003 & 4.2 & 0.8 & 0.026 & 4.4 \\
\hline Fenoprofen glucuronide & 0.7 & 0.005 & 3.4 & 1.4 & 0.013 & 3.9 & & & & & & & \\
\hline L-Carnitine & 0.9 & 0.019 & -3.3 & 1.2 & 0.01 & -3.2 & Fenoprofen glucuronide & 0.7 & 0.003 & 3.6 & 0.8 & 0.01 & 3.1 \\
\hline APGPR Enterostatin & 1.1 & 0.005 & -3 & 1.5 & 0.013 & -4 & Tyrosyl-Valine & 0.3 & 0.019 & 3.4 & 0.3 & 0.033 & 1.9 \\
\hline Hippuric acid & 0.9 & 0.048 & 2.4 & 1.6 & 0.013 & 2.7 & $\begin{array}{l}\text { 3-Methoxy-4- } \\
\text { hydroxyphenylethyleneglycol sulfate }\end{array}$ & 0.7 & 0.03 & 3.2 & 0.9 & 0.042 & 2.7 \\
\hline $\begin{array}{l}\text { 3,4-Dihydroxyphenylglycol } \\
\text { O-sulfate }\end{array}$ & 0.5 & 0.005 & 2.4 & 0.4 & 0.036 & 1.2 & Hippuric acid & 1.2 & 0.003 & 3.2 & 1.2 & 0.012 & 2.5 \\
\hline Isovalerylalanine & 0.5 & 0.005 & -2.3 & 0.8 & 0.013 & -2.2 & & & & & & & \\
\hline
\end{tabular}

$p$-value* $: p$-value for Exact Wilcoxon Rank Sum Test

FC**: A positive or negative fold change indicates median of STZ > median of $\mathrm{NaC}$ 


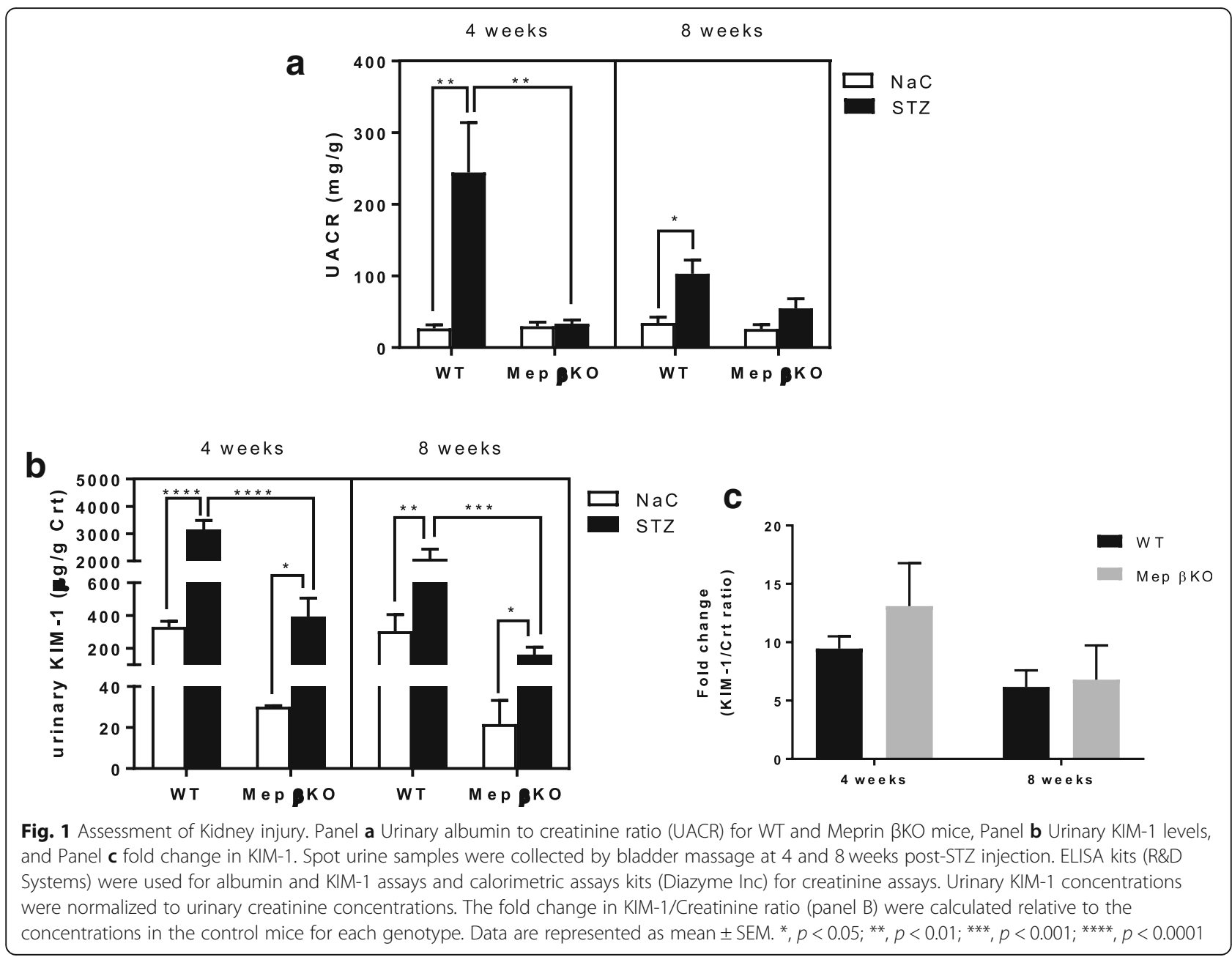

metabolites at 8 weeks post-STZ when compared to 4 weeks post-STZ, suggesting an association with severity of complications of diabetes (Table 3).

\section{Meprin expression-associated differentiating metabolites in plasma}

Metabolites with changed levels in either WT or meprin $\beta \mathrm{KO}$ mice only were considered to be associated with meprin $\beta$ expression/activity or meprin $\beta$ deficiency. While plasma PCA and OPLS-DA models or diabetes status were overall of good quality (Table 1. Plasma model statistics; Fig. 3), PCA models showed the source of variability on components 1 and 2 in the positive mode datasets was not treatment group. At 4 weeks post-STZ injection there were significant changes in the levels of 159 plasma metabolites in WT mice only (7 annotated, 152 of unknown identity) (Fig. 3 panel B). Although seven of the annotated plasma metabolites (Table 4) had a $1.5 \leq$ FC, they all had VIP $\leq 1$ scores, suggesting that they are not strong predictors. The number of differentiating metabolites in the plasma of WT mice at 8 weeks was much higher (16 annotated, 358 unknown). Fifteen of the annotated metabolites had $1.5 \leq$ FC but only three had a $2 \leq$ VIP score, making them strong predictors. These three are; LysoPC(16:1(9Z)) $(\mathrm{FC}=-3.6 ; \mathrm{VIP}=3)$, taurocholic acid $(\mathrm{FC}=2.5 ; \mathrm{VIP}=$ $3.2)$, and indoxyl sulfate $(\mathrm{FC}=2.1 ; \mathrm{VIP}=5.3)$. Of the 198 differentiating metabolites in the plasma of meprin $\beta \mathrm{KO}$ at 4 weeks, only 9 were annotated, and at 8 weeks, only one out of 147 metabolites was annotated. Furthermore, none of the identified metabolites had a $2 \leq$ VIP score.

\section{Differentiating plasma metabolites independent of meprin expression}

The levels of several metabolites were significantly changed in the plasma of both WT and meprin $\beta \mathrm{KO}$ mice indicating that the changes are associated with the diabetic status but independent of meprin expression/activity or deficiency (Table 5). Of the annotated metabolites at four weeks post-STZ, only one metabolite had $1.5 \leq \mathrm{FC}$ and a $2 \leq$ VIP score in both genotypes, namely; LysoPC $(16: 1(9 \mathrm{Z})) \quad(\mathrm{FC}=4.8 ; \quad \mathrm{VIP}=5.1) . \quad$ Of $\quad$ interest 


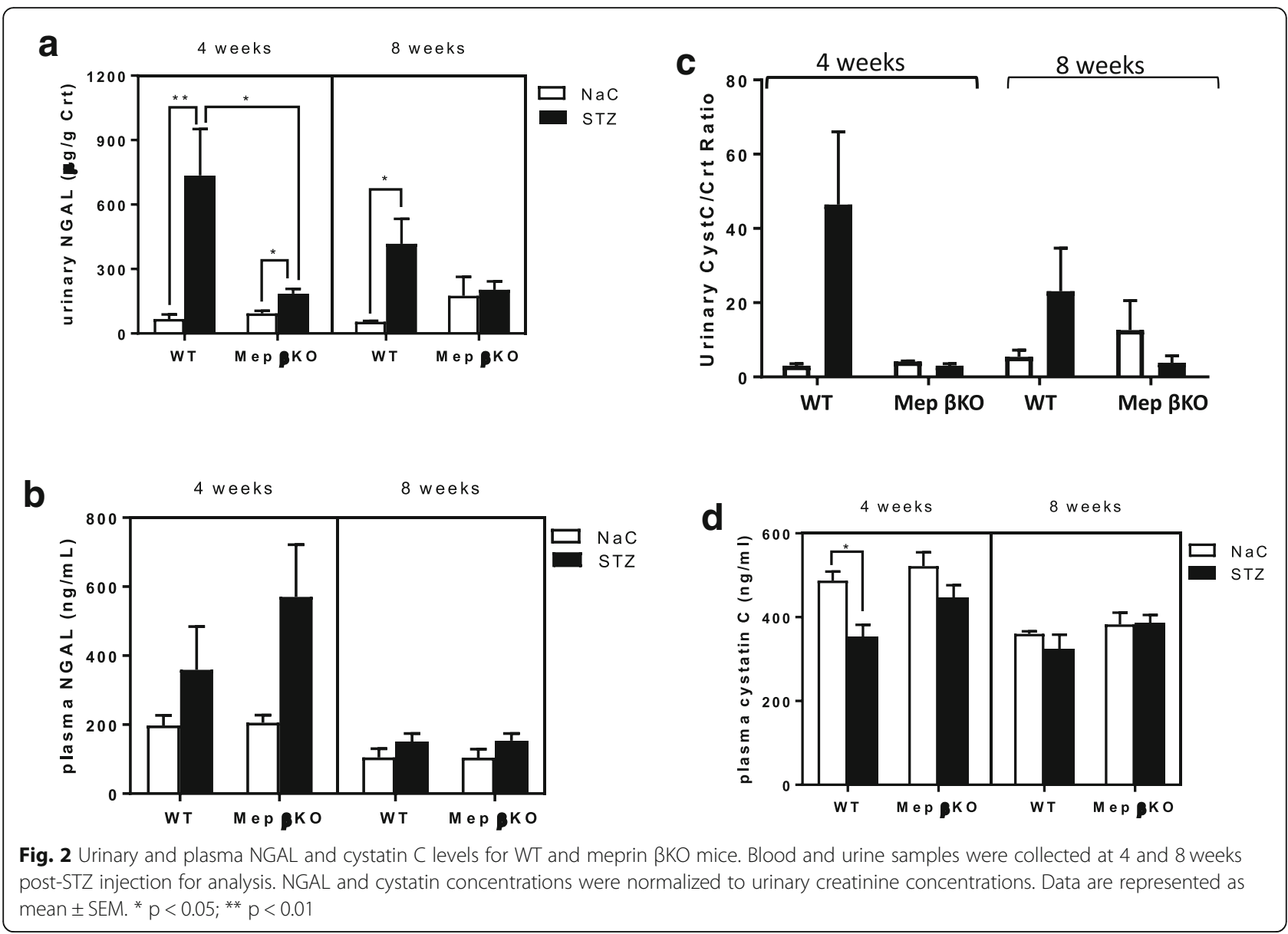

though, hippuric acid showed significant increases in both genotypes at 4 and 8 weeks post-STZ with fairly strong VIP scores at 8 weeks. Several other metabolites had significant FC in both genotypes but their VIPs were low. For example, at 4 weeks, indole-3-carboxilic acid-O-sulphate had a FC $=4.7$ in WT and FC $=10.43$ in $\beta \mathrm{KO}$ and at 8 weeks it had a $\mathrm{FC}=6.2$ in WT and $\mathrm{FC}=$ 935.1 in $\beta K O$.

\section{Meprin expression-associated differentiating metabolites in urine}

There were distinct changes in metabolite profiles in urine samples from diabetic mice when compared to non-diabetic $\mathrm{NaC}$ treated control mice of the same genotype (Tables 3, 6, and 7). Of the annotated metabolites in urine samples from WT mice at 4 weeks, 27 had $1.5 \leq \mathrm{FC}$ with 10 having $2.0 \leq$ VIP scores. At 8 weeks, fifteen metabolites had $1.5 \leq \mathrm{FC}$ with nine having $2 \leq \mathrm{VIP}$ scores. Twenty five of the metabolites had significant changes in levels at both 4 and 8 weeks (Table 7) post-STZ suggesting that they are reliably associated with $\mathrm{DN}$ and perhaps other complications of diabetes. However, only three of these had $2 \leq$ VIP scores at both time points, namely; cortisol, homovanillic acid sulfate, phloretin 2'-O-glucuronide and are thus considered strong predictors for early onset of complications of diabetes such as DN. Interestingly the three identified metabolites that significantly changed levels in the urine of $\beta \mathrm{KO}$ mice at 4 weeks all had a $\mathrm{FC} \leq 1.5$ even though all their VIP scores were greater than 2 and their levels were not significantly changed at 8 weeks (Additional file 1: Tables S1, S2, S3,S4, S5, S6, S7 and S8). At 8 weeks, there were significant decreases in the levels of three metabolites (which also had strong VIP scores) in urine from $\beta K O$ mice; 3,5-Dihydroxy-3',4'-dimethoxy-6,7-methylenedioxyflavone 3 -glucuronide $(\mathrm{FC}=-3.7 ; \mathrm{VIP}=5.6)$, pantothenic acid $(\mathrm{FC}=-1.7, \quad \mathrm{VIP}=4.1), \quad$ and indoxyl glucuronide $(\mathrm{FC}=-1.7 ; \mathrm{VIP}=3.2)$.

\section{Differentiating urine metabolites independent of meprin expression}

There were distinct changes in the profiles of several metabolites in urine for both WT and meprin $\beta \mathrm{KO}$ mice at both 4 weeks (33 annotated, 193 unknown) and 8 weeks post-STZ injection (53 annotated, 1315 unknown) (Tables 3 and 7, and Addiitonal file 1: Tables S5-S8). Nine metabolites had $1.5 \leq \mathrm{FC}$ and $2 \leq$ VIP score at both 4 and 8 weeks post-STZ suggesting a strong association with diabetes and diabetes associated-complications such as DN but 


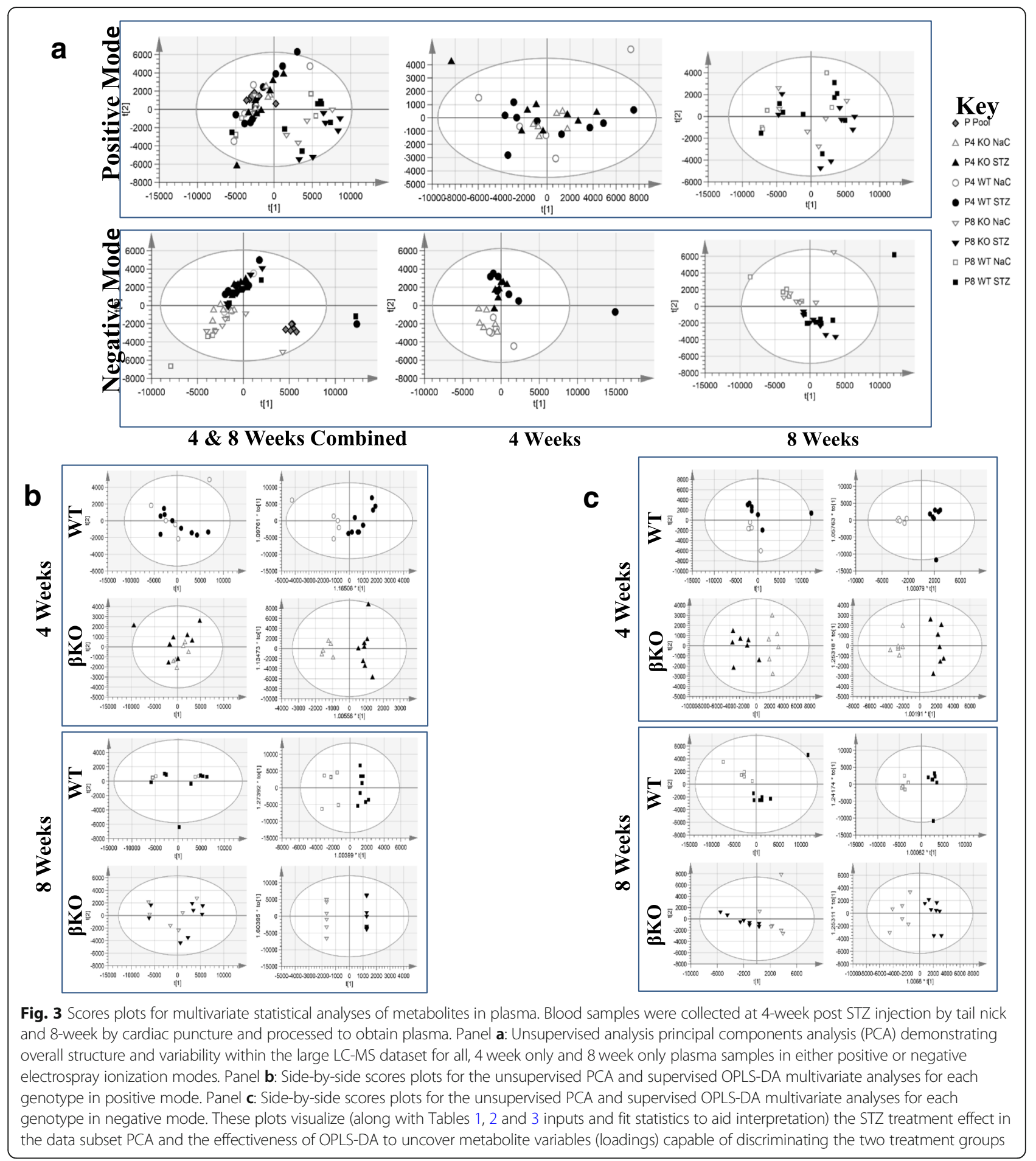

independent of meprin $\beta$ expression/activity or deficiency. The nine are; a-L-threo-4-Hex-4-enopyranuronosyl-Dgalacturonic acid, 1-Pyrroline-4-hydroxy-2-carboxylate, Glycerophosphocholine, Nicotinic acid, Indole-3-carboxylic acid, Galactonic acid, Genistein 5-O-glucuronide, $\mathrm{N}$-Acetylleucine, and Equol 7-O-glucuronide.

\section{Meprin expression-associated metabolites that changed} in both plasma and urine

Only 3 metabolites had changed profiles in both plasma and urine. The levels of $\mathrm{N}$-heptanoylglycine decreased mice at 4 weeks post-STZ in biofluids from WT mice $(\mathrm{FC}=-5.2$ in plasma vs $\mathrm{FC}=-3.9$ in urine). However, the VIP scores in 


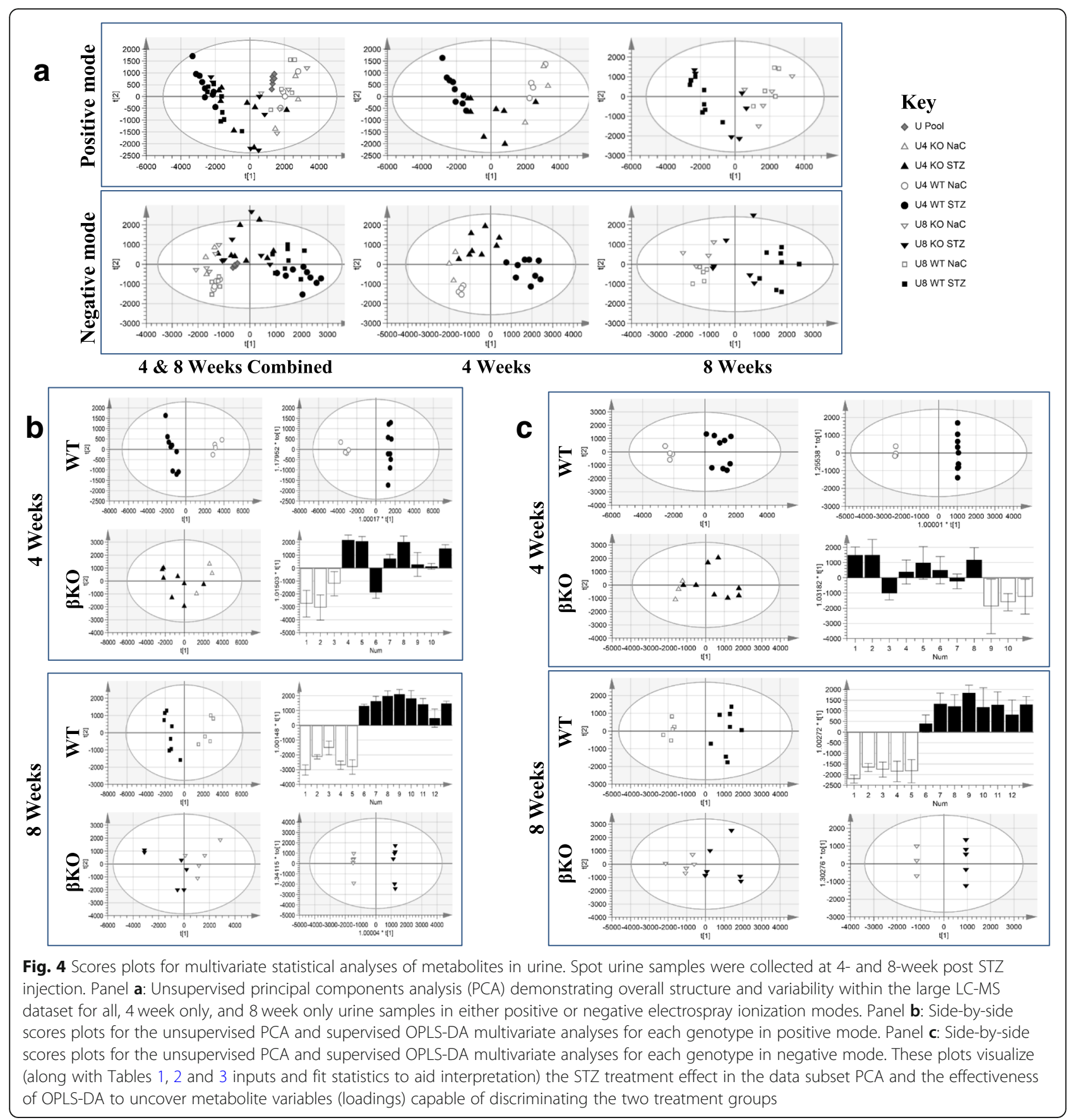

plasma were low (VIP $=0.6$ vs VIP $=4.7$ in urine). In contrast, the levels of taurocholic acid in WT mice increased at 8 weeks post-STZ with comparable FC values (2.5 in plasma 2.0 in urine) and a stronger VIP score in plasma (3.2 in plasma vs 0.3 in urine). For meprin deficient mice, the levels of 3-Methoxy-4-hydroxyphenylethyleneglycol sulfate increased at 4 weeks post-STZ $(\mathrm{FC}=3.3, \mathrm{VIP}=1.7$ in plasma; $\mathrm{FC}=1.3$, VIP $=14.2$ in urine). TCA has previously been shown to discriminate polycystic rat kidneys from healthy kidneys [45]. Another interesting observation was the fact that changes in the levels of the differentiating urine metabolites occurred earlier in diabetic WT mice when compared to meprin $\beta \mathrm{KO}$ counterparts. There were 22 annotated metabolites whose levels changed in the urine of WT mice at 4-week and 8-week post STZ but these changes only showed in meprin $\beta K O$ mice at 8-week post STZ. (Additional file 1: Tables S1, S2, S3,S4, S5, S6, S7 and S8). This suggests that meprin $\beta$ deficiency results in a late onset of diabetes-associated complications. 
Table 6 Summary of differentiating urinary metabolites in WT and meprin $\beta K O$ mice at 4- and 8-weeks post STZ with a $2 \leq$ FC and/ or $2 \leq$ VIP. A variable importance in projection (VIP) score $2 \leq$ are considered to have strong predictive value. Differentiating urinary metabolites that associate with meprin expression (Change in either WT or $\beta K O$ only)

\begin{tabular}{|c|c|c|c|c|c|c|c|c|}
\hline & \multicolumn{4}{|l|}{4 Weeks post STZ } & \multicolumn{4}{|l|}{8 Weeks post STZ } \\
\hline & & VIP & $P$-value* & $\mathrm{FC}^{* *}$ & & VIP & $P$-value* & $F C^{* *}$ \\
\hline \multirow{20}{*}{$\begin{array}{l}\text { WT } \\
\text { Only }\end{array}$} & Cortisol & 10.5 & 0.003 & 54.9 & Cortisol & 8.2 & 0.002 & 21.6 \\
\hline & $\begin{array}{l}\text { 9,13-Dihydroxy-4-megastigmen-3-one 9- } \\
\text { glucoside }\end{array}$ & 1.6 & 0.003 & -22.9 & Homovanillic acid sulfate & 7.8 & 0.002 & 21 \\
\hline & Aromadendrin 3,7-diglucoside & 1.3 & 0.02 & 6.9 & Aromadendrin 3,7-diglucoside & 2 & 0.002 & 13.9 \\
\hline & Hydroxybutyrylcarnitine & 1 & 0.003 & -6.2 & Pyrogallol-2-O-glucuronide & 1.5 & 0.006 & -3.5 \\
\hline & Homovanillic acid sulfate & 8.3 & 0.02 & 4.1 & Phloretin 2'-O-glucuronide & 1.3 & 0.002 & 3.4 \\
\hline & Taurocholic acid & 0.5 & 0.003 & 4 & Prenyl glucoside & 2 & 0.002 & -3.1 \\
\hline & $\mathrm{N}$-Heptanoylglycine & 4.7 & 0.011 & -3.9 & Caffeic acid 3-sulfate & 4.7 & 0.002 & 2.3 \\
\hline & Cicerin 7-(6-malonylglucoside) & 3.5 & 0.003 & 3.7 & 4-Hydroxyphenylpyruvic acid & 1.7 & 0.003 & 2.3 \\
\hline & Porric acid B & 3.3 & 0.003 & -3.7 & Tyrosyl-Valine & 1.4 & 0.006 & 2.3 \\
\hline & Phloretin 2'-O-glucuronide & 1.2 & 0.003 & 3.6 & Dibutyl malate & 1.7 & 0.002 & 2.1 \\
\hline & Phenylacetylglycine & 0.4 & 0.003 & -3.4 & Ergothioneine & 0.3 & 0.002 & 2.1 \\
\hline & 20-oxo-leukotriene B4 & 2.1 & 0.003 & 3.3 & Taurocholic acid & 0.3 & 0.002 & 2 \\
\hline & Tyrosyl-Valine & 1.8 & 0.003 & 3.3 & Indole-3-carboxilic acid-O-sulphate & 4.9 & 0.002 & 1.9 \\
\hline & LysoPC(16:1(9Z)) & 0.5 & 0.003 & 2.9 & 7-Methoxy-5-prenyloxycoumarin & 2.4 & 0.002 & 1.9 \\
\hline & $\begin{array}{l}\text { 3b,8b-Dihydroxy-6b-angeloyloxy-7(11)- } \\
\text { eremophilen-12,8-olide }\end{array}$ & 1.8 & 0.003 & 2.7 & 5-Acetyl-2,4-dimethyloxazole & 2.2 & 0.002 & 1.7 \\
\hline & Indole-3-carboxilic acid-O-sulphate & 1.7 & 0.003 & 2.7 & $\begin{array}{l}\text { 3,5-Dihydroxy-3',4'-dimethoxy-6,7- } \\
\text { methylenedioxyflavone 3-glucuronide }\end{array}$ & 5.6 & 0.004 & -3.7 \\
\hline & Caffeic acid 4-sulfate & 2.5 & 0.003 & -2.7 & 3-Formyl-6-hydroxyindole & 1.2 & 0.017 & 3.6 \\
\hline & Phenylpropionylglycine & 4.8 & 0.011 & -2.4 & Formononetin 7-O-glucuronide & 2.3 & 0.004 & 1.7 \\
\hline & Ergothioneine & 0.3 & 0.003 & 2.1 & Indoxyl glucuronide* & 3.2 & 0.004 & -1.7 \\
\hline & Hippuric acid & 1.4 & 0.034 & -2 & & & & \\
\hline \multirow{3}{*}{$\begin{array}{l}\beta K O \\
\text { Only }\end{array}$} & 4-Methoxyphenylacetic acid & 2.3 & & 1.4 & & & & \\
\hline & $\begin{array}{l}\text { 3-Methoxy-4-hydroxyphenylethyleneglycol } \\
\text { sulfate }\end{array}$ & 14.2 & & 1.3 & & & & \\
\hline & Riboflavin & 2.5 & & -1.3 & & & & \\
\hline
\end{tabular}

$p$-value* $: p$-value for Exact Wilcoxon Rank Sum Test

FC**: A positive or negative fold change indicates median of STZ $>$ median of $\mathrm{NaC}$

\section{Metabolic pathways impacted by meprin expression}

The annotated metabolites with significantly changed profiles are associated with several metabolic pathways (Table 8). These include; amino acid metabolism, protein degradation, lipid metabolism, nucleotide metabolism, vitamin metabolism, hormone/neurotransmitter, and small molecule metabolites typically dietary sources or gastrointestinal tract/gut microbiota.

\section{Discussion}

Meprin metalloproteases have been shown to play a role in the pathology of diabetic nephropathy (DN) in humans and in mouse models of DN $[8,9,12]$. However, knowledge of underlying mechanisms is limited. Known meprin $\beta$ substrates includes several ECM proteins (e.g., collagen II, Collagen IV, laminin, fibronectin, and nodogen-1) [46] and inflammatory mediators (e.g., IL-6, pro-IL18, MCP-1, and thymosin $\beta 4 /$ Ac-SDKP) [28]. Imbalances in ECM metabolism and inflammation both contribute to the fibrosis observed in DN. Other meprin targets e.g. protein kinase $\mathrm{C}$ (PKC) [21] and the catalytic subunit of protein kinase A (PKA C) $[13,22,23]$ modulate signaling pathways involved in inflammation and ECM metabolism. However, it's not known how proteolytic processing of meprin targets impacts the metabolite environment in the kidneys and other sites where meprins are expressed. The current study employed global metabolomics analysis to evaluate the metabolite profiles of urine and plasma samples from WT mice (which express normal levels of both meprin $\mathrm{A}$ and meprin $\mathrm{B}$ ) and meprin $\beta \mathrm{KO}$ mice which are deficient in meprin $B(\beta-\beta)$ and heterodimeric meprin $A(\alpha-\beta)$ 
Table 7 Summary of differentiating urinary metabolites in WT and meprin $\beta K O$ mice at 4- and 8-weeks post STZ with a $2 \leq$ FC and/ or $2 \leq$ VIP. A variable importance in projection (VIP) score $2 \leq$ are considered to have strong predictive value. Differentiating Urinary metabolites that are independent of meprin $\beta$ expression (levels change in both WT and meprin $\beta K O$ mice)

\begin{tabular}{|c|c|c|c|c|c|c|c|c|c|c|c|c|}
\hline \multicolumn{6}{|l|}{4 Weeks post STZ } & \multicolumn{7}{|l|}{8 weeks post-STZ } \\
\hline & \multicolumn{3}{|l|}{ WT } & \multicolumn{2}{|l|}{$\beta K O$} & & \multicolumn{3}{|l|}{ WT } & \multicolumn{3}{|c|}{$\beta K O$} \\
\hline & VIP & $P$-value* & $\mathrm{FC}^{* *}$ & VIP $P$-value* & $\mathrm{FC}^{* *}$ & & VIP & $P$-value* & $\mathrm{FC}^{* *}$ & VIP & $P$-value* & $\mathrm{FC}^{* *}$ \\
\hline $\begin{array}{l}\text { a-L-threo-4-Hex-4- } \\
\text { enopyranuronosyl-D- } \\
\text { galacturonic acid }\end{array}$ & 2.8 & 0.003 & - & 3.9 & -20.8 & $\begin{array}{l}\text { a-L-threo-4-Hex-4- } \\
\text { enopyranuronosyl-D- } \\
\text { galacturonic acid }\end{array}$ & 2.4 & 0.003 & -22.5 & 3.3 & 0.052 & -4.3 \\
\hline S-(Formylmethyl)glutathione & 1.4 & 0.003 & -31 & 2.7 & -5.6 & $\begin{array}{l}\text { 9,13-Dihydroxy-4- } \\
\text { megastigmen-3-one 9- } \\
\text { glucoside }\end{array}$ & 1.7 & 0.002 & -19.1 & 1.5 & 0.004 & -3.5 \\
\hline $\begin{array}{l}\text { 1-Pyrroline-4-hydroxy-2- } \\
\text { carboxylate }\end{array}$ & 2.5 & 0.003 & -13.2 & 2.6 & -3.6 & S-(Formylmethyl)glutathione & 1.2 & 0.002 & -8.4 & 2.6 & 0.126 & -2.3 \\
\hline Avenic acid B & 1.4 & 0.003 & -7.3 & 2.5 & -4.8 & $\begin{array}{l}\text { 1-Pyrroline-4-hydroxy-2- } \\
\text { carboxylate }\end{array}$ & 2.6 & 0.002 & -7.7 & 2.1 & 0.017 & -2.8 \\
\hline Glycerophosphocholine & 3.9 & 0.003 & -6.9 & 2.6 & -3 & Hydroxybutyrylcarnitine & 1.1 & 0.002 & -6.5 & 1.7 & 0.004 & -5.4 \\
\hline Nicotinic acid & 3.3 & 0.003 & -5.9 & 3.8 & -3.1 & Cicerin 7-(6-malonylglucoside) & 4 & 0.006 & 5.8 & 1.4 & 0.004 & 1.8 \\
\hline Indole-3-carboxylic acid & 2.4 & 0.003 & -4.8 & 2.3 & -2.2 & Avenic acid B & 1.5 & 0.002 & -5.8 & 1.5 & 0.009 & -1.7 \\
\hline Pyrogallol-2-O-glucuronide & 1.7 & 0.003 & -4.8 & 2.2 & -2.6 & Glycerophosphocholine & 4 & 0.002 & -4.8 & 4.1 & 0.017 & -2.2 \\
\hline $\mathrm{N}$-a-Acetyl-L-arginine & 2.9 & 0.003 & -3.3 & 2.4 & -1.6 & Indole-3-carboxylic acid & 2.7 & 0.002 & -4.8 & 2.5 & 0.004 & -3 \\
\hline $\begin{array}{l}\text { N-Carboxyethyl-g- } \\
\text { aminobutyric acid }\end{array}$ & 1.5 & 0.003 & -3.3 & 2.2 & -2.8 & $\begin{array}{l}\mathrm{N} \text {-Carboxyethyl-g- } \\
\text { aminobutyric acid }\end{array}$ & 2 & 0.002 & -4.8 & 1.8 & 0.03 & -1.8 \\
\hline Galactonic acid & 4.3 & 0.003 & -3.1 & 5.2 & -2.5 & Nicotinic acid & 3.3 & 0.002 & -3.6 & 3.9 & 0.004 & -2.4 \\
\hline 4-Hydroxyphenylpyruvic acid & 2.5 & 0.003 & 2.6 & 2.2 & 4.8 & Porric acid B & 3.5 & 0.002 & -3.4 & 3.3 & 0.052 & -1. \\
\hline Symmetric dimethylarginine & 3.5 & 0.003 & -2.6 & 4.3 & -2.3 & 1,3,5-Trimethoxybenzene & 2.1 & 0.002 & -3.1 & 1.5 & 0.009 & -1.6 \\
\hline $\begin{array}{l}\text { 7-Methoxy-5- } \\
\text { prenyloxycoumarin }\end{array}$ & 2.6 & 0.003 & 2.5 & 2.3 & 1.6 & Phenylacetylglycine & 0.4 & 0.002 & -3 & 0.4 & 0.004 & -2.6 \\
\hline Indoxylglucuronide & 1.8 & 0.034 & -2.5 & 3.5 & -2 & N-Acetylleucine & 6.4 & 0.006 & 2.7 & 5.2 & 0.329 & 1.3 \\
\hline Caffeic acid 3-sulfate & 6.6 & 0.003 & 2.4 & 5.8 & 4.2 & 20-oxo-leukotriene B4 & 1.7 & 0.003 & 2.6 & 1.8 & 0.009 & 2.3 \\
\hline Genistein 5-O-glucuronide & 3.2 & 0.003 & 2.3 & 2.9 & 1.2 & $\mathrm{~N}$-Heptanoylglycine & 4.4 & 0.006 & -2.6 & 6.7 & 0.017 & -3.9 \\
\hline N-Acetylleucine & 7.5 & 0.02 & 2.2 & 7 & 2 & $\begin{array}{l}\text { Indole-3-carboxilic acid-O- } \\
\text { sulphate }\end{array}$ & 1.8 & 0.002 & 2.4 & 0.6 & 0.004 & 3.3 \\
\hline Betaine & 4.1 & 0.006 & 2 & 3.2 & 1.5 & L-Carnitine & 4.6 & 0.002 & -2.4 & 6.2 & 0.03 & -1.7 \\
\hline $\begin{array}{l}\text { Indole-3-carboxilic acid-O- } \\
\text { sulphate }\end{array}$ & 3.9 & 0.02 & 1.6 & 2.4 & 1.8 & D-1,5-Anhydrofructose & 0.5 & 0.003 & -2.2 & 1.1 & 0.004 & -2.3 \\
\hline 5-Acetyl-2,4-dimethyloxazole & 2.3 & 0.003 & 1.7 & 2.6 & 1.7 & Galactonic acid & 3.8 & 0.003 & -2.1 & 4.2 & 0.177 & -2.1 \\
\hline Lotaustralin & 2.5 & 0.003 & 1.8 & 2.4 & 1.6 & Genistein 5-O-glucuronide & 2.6 & 0.03 & 1.8 & 3.3 & 0.004 & 1.6 \\
\hline Fenoprofen glucuronide & 6.7 & 0.003 & 1.6 & 10 & 1.5 & Equol 7-O-glucuronide & 3.5 & 0.003 & 1.7 & 4.6 & 0.004 & 1.5 \\
\hline \multirow[t]{2}{*}{ Equol 7-O-glucuronide } & 3.2 & 0.003 & 1.6 & 4.1 & 1.5 & Isovalerylalanine & 4.7 & 0.03 & -1.5 & 7.6 & 0.052 & -3.7 \\
\hline & & & & & & Indolelactic acid & 4.6 & 0.065 & -1.5 & 5.8 & 0.082 & -1.5 \\
\hline
\end{tabular}

$p$-value $: p$-value for Exact Wilcoxon Rank Sum Test

FC**: A positive or negative fold change indicates median of $\mathrm{STZ}>$ median of $\mathrm{NaC}$

following induction of type 1 diabetes. Blood and urine samples were obtained at 4 and 8 weeks post-STZ which would correspond to early onset of kidney injury. Biochemical assessment of kidney injury using UACR and recently developed proteomic markers (NGAL, KIM-1, and cystatin $\mathrm{C}$ ) confirmed kidney injury as early as four weeks post-STZ injection. Of the proteomic biomarkers assayed, urinary NGAL and urinary KIM-1 positively correlated with kidney injury and are thus reliable predictors of early diabetic kidney injury. An interesting finding was the high baseline levels of KIM-1 in the non-diabetic WT mice, suggesting that meprins $\beta$ could predispose kidneys to tubular injury. The data further suggest that deficiency of meprin $\beta$ can alleviate the progression of $\mathrm{DN}$. A previous study with meprin $\alpha \beta$ double knockout mice showed that deficiency of both meprin $\alpha$ 
Table 8 Summary of metabolic pathways for metabolites with significant changes in levels that associate with meprin $\beta$ expression or deficiency and STZ-induced type 1 diabetes

\begin{tabular}{|c|c|c|}
\hline Metabolite & Increase/decrease & Pathways \\
\hline \multicolumn{3}{|c|}{ Group 1: changed levels in plasma associate with meprin expression or deficiency } \\
\hline Taurocholic acid & Increases in WT & Bile acids/lipid metabolism \\
\hline LysoPC(16:1(9Z)) & Decreases in WT & Lipid metabolism \\
\hline Indoxyl sulfate & Increases in WT & oxidative stress \\
\hline \multicolumn{3}{|c|}{ Group 2: 8 changes in urine associate with meprin $\beta$ expression or deficiency } \\
\hline Taurocholic acid ${ }^{\mathrm{a}}$ & Increase in WT & Bile acids (lipid metabolism) \\
\hline Ergothioneine $^{a}$ & Increase in WT & Gut/dietary source (histidine metabolism) \\
\hline Tyrosyl-Valine ${ }^{a}$ & Increase in WT & Protein degradation (aromatic amino acid metabolism) \\
\hline Prenyl glucoside & Decrease in WT & Gut/dietary (fatty acyl glucoside) \\
\hline Homovanillic acid sulfate & increase in WT & Catecholamine metabolism \\
\hline Cortisol & Increase in WT & Steroid hormone synthesis/stress response \\
\hline Aromadendrin 3,7-diglucoside & Increase in WT & Gut/dietary (flavonoid) \\
\hline Phloretin 2'-O-glucuronide ${ }^{a}$ & Increase in WT & Gut/dietary (flavonoid) \\
\hline $\begin{array}{l}\text { 3,5-Dihydroxy-3',4'-dimethoxy-6,7- methylenedioxyflavone } \\
\text { 3-glucuronide }\end{array}$ & Decrease in $\beta K O$ & Gut/dietary \\
\hline Pantothenic acid & Decrease in $\beta K O$ & Gut/dietary \\
\hline Indoxyl glucuronide & Decrease in $\beta K O$ & Indole metabolism/gut microbiota \\
\hline \multicolumn{3}{|c|}{ Group 3: changed levels in plasma associate with STZ-induced type 1 diabetes but independent of meprin $\beta$ expression } \\
\hline Hippuric acid ${ }^{a}$ & $\begin{array}{l}\text { Increase at } 4 \text { and } 8 \\
\text { weeks }\end{array}$ & $\begin{array}{l}\text { Amino acid metabolism (phenylalanine polyphenol } \\
\text { metabolism; uremia) }\end{array}$ \\
\hline Indole-3-carboxilic acid-O-sulphate ${ }^{a}$ & Increase & Indole metabolism \\
\hline Fenoprofen glucuronide ${ }^{a}$ & Increase & NSAID metabolite \\
\hline \multicolumn{3}{|c|}{ Group 4: Changed levels in urine associate with STZ-induced type 1 diabetes but independent of meprin $\beta$ expression } \\
\hline Glycerophosphocholine & Decrease & $\begin{array}{l}\text { Lipid metabolism (choline metabolism; } \\
\text { glycerophosphocholine) }\end{array}$ \\
\hline Nicotinic acid & Decrease & $\begin{array}{l}\text { Co-factor and vitamin (nicotinate and nicotinamide } \\
\text { metabolism) }\end{array}$ \\
\hline 1-Pyrroline-4-hydroxy-2-carboxylate & Decrease & Amino acid metabolism (arginine and proline metabolism) \\
\hline Indole-3-carboxylic acid & Decrease & Gut/Dietary (indole metabolism) \\
\hline a-L-threo-4-Hex-4-enopyranuronosyl-D-galacturonic acid & Decrease & Carbohydrate metabolism (glucuronic acid derivative) \\
\hline
\end{tabular}

${ }^{a} \mathrm{VIP} \leq 2$ but consistent significant increases at both 4 and 8 weeks post STZ

and meprin $\beta$ resulted in more severe kidney injury [47]. While these findings appear to be contradictory, they point to the isoform-specific impact of meprins. Several studies have demonstrated that inflammation is an underlying mechanism in the progression of diabetic kidney injury. Meprin A has anti-inflammatory activities $[28,48]$ while meprin B plays both pro-inflammatory $[24,27]$ and anti-inflammatory [26] roles. It has further been shown that the balance of meprin A and meprin B influences the progression of inflammatory bowel disease in experimental mice [49]. It is thus likely that deficiency in meprin B and heterodimeric meprin A $(\alpha-\beta)$ tilts the balance toward anti-inflammation activities driven by homomeric meprin $\mathrm{A}(\alpha-\alpha)$ and thus protects from injury in diabetic kidney disease. This is supported by the finding that meprin A plays a role in the release of the anti-inflammatory peptide ac-SDKP from thymosine $\beta 4$ [28].

The findings of the current global metabolomics analysis of plasma and spot urine samples from diabetic WT and meprin $\beta K O$ mice offer insights into the metabolic alterations occurring in diabetes and the role that meprin $\beta$ plays in modulating diabetic kidney injury and other complications of diabetes. An important finding from the current study is diabetes-associated changes in the levels of 5 plasma metabolites and 25 urinary metabolites unique to WT mice, suggesting an association with meprin $\beta$ expression/activity. Many of these metabolites have also been previously reported in association with diabetes, which supports a role of meprin $\beta$ in modulating the progression of complications of diabetes such as DN. Furthermore, the data suggest that meprin $\beta$ impacts diverse 
pathways, which include lipid metabolism, amino acid metabolism, nucleotide metabolism, and vitamin metabolism. Diabetes-associated changes in the levels of taurocholic acid, a bile acid, were only significant in WT mice. Furthermore, taurocholic acid was the only metabolite with changed levels in both urine and plasma at both 4 and 8 weeks post-STZ injection. Multiple studies showed that specific bile acids like taurocholic acid stimulate bicarbonate secretion and bile flow [50]. In another study, patients with type 2 diabetes showed higher plasma taurocholic acid levels when compared to healthy subjects [51]. Taurocholic acid has also been shown to discriminate polycystic rat kidneys from healthy kidneys [45], suggesting a link to renal fibrosis. Given the function of bile acid in promoting lipid metabolism, the resistance of meprin $\beta K O$ mice to taurocholic acid alteration could contribute to other differences in lipid profiles. This resistance is likely linked to meprin expression in the small intestines rather than in kidney tissue. Among the metabolites associated with amino acid metabolism are kynurenic acid, indoxyl sulfate, and hippuric acid. Kynurenic acid is a metabolite of tryptophan and it has been identified as a kidney function marker in several studies [52, 53]. In the current study, urinary kynurenic acid levels decreased in diabetic WT mice at both 4 and 8 weeks, but not in diabetic meprin $\beta K O$ mice. This change indicates compromised kidney function in amino acid metabolism, but also suggests meprin $\beta$ may mediate the metabolism of tryptophan. Furthermore, the levels of indoxyl sulfate increased in urine from WT mice at both 4- and 8-week post STZ, while its levels increased in urine from meprin $\beta \mathrm{KO}$ mice at 8 -week but not 4-week post STZ. In plasma, the increased levels of indoxyl sulfate were found only in WT mice at 8 -week post STZ. Indoxyl sulfate is also a metabolite of tryptophan, considered a microbiota-derived uremic solute and related with chronic kidney disease [54]. In patients with chronic kidney disease, the serum and urine levels of indoxyl sulfate increased markedly and were shown to promote the progression of renal failure $[55,56]$. The differences in indoxyl sulfate level changes in the current study indicate the late onset of kidney injury in meprin $\beta K O$ mice when compared to WT mice. The levels of hippuric acid increased in the urine of WT mice at both 4- and 8-week. Hippuric acid is involved in phenylalanine metabolism, considered a microbiota-derived uremic solute and related to chronic kidney disease [54]. Both hippuric acid and its precursor benzoic acid have been implicated in early-stage DN [43]. Plasma levels of hippuric acid were shown to be elevated in haemodialysed patients with chronic renal failure when compared to healthy controls and hospital patients without kidney disease [57]. Several differentiating metabolites are involved in vitamin metabolism. We did not observe changes in urinary excretion of riboflavin in WT mice, but the urinary excretion of riboflavin in meprin $\beta \mathrm{KO}$ mice decreased at both 4 weeks and 8 weeks. Meanwhile, riboflavin level in the plasma of WT mice increased at 8 weeks post-STZ injection. Increased urinary excretion of riboflavin was previously observed in rats with STZ-induced diabetes [58]. Furthermore, dietary riboflavin was shown to have protective effects on $\mathrm{DN}$ in STZ-induced diabetic rats [59]. Thus, if the decreased urinary riboflavin is caused by the body conservation of riboflavin, it may protect meprin $\beta$ null mice against diabetic kidney injury. Changes in the levels of N1-methyl-pyridone-3-carboxamide, indicate the involvement of meprin $\beta$ on vitamin B6 catabolism, nicotinamide-adenine dinucleotide degradation, and biotin metabolism in response to diabetic conditions [60]. The changes of multiple vitamin metabolites suggest system wide mediation of meprin $\beta$. This could be via impacting of microbial populations in the small intestines where meprins are abundantly expressed. Meprin $\beta$ in the small intestine is required for detachment of mucin, which is important for protecting the host epithelium from bacteria [61]. Such protective function of meprin $\beta$ also corroborates the different microbial populations between WT and meprin $\beta K O$ mice. Another interesting finding in the current study is meprin expression associated changes in the profiles of several hormone or neurotransmitter metabolites, such as cortisol, and homovanillic acid sulfate. Previous studies demonstrated that serum cortisol levels were significantly related to retinopathy and neuropathy, but not nephropathy [62]. The fold change in urinary cortisol levels was significant in WT mice at both 4- and 8-weeks post-STZ (54.9 and 21.6), while no such alteration was seen in meprin $\beta$ null mice. Furthermore, the fold change in plasma cortisol was more significant in WT than meprin $\beta$ null mice at 4 weeks post-STZ ( 23.2 vs 2.4). 3-Methoxy-4-hydroxyphenylethyleneglycol sulfate is a major metabolite of noradrenaline. Its formation in brain is used as an estimate of the norepinephrine formation rate [63]. It was also identified as a potential marker for uremia. It significantly increased in subjects with end stage renal disease when compared with healthy controls [64]. Homovanillic acid sulfate is a major catecholamine metabolite while urinary homovanillic acid sulfate was shown to be a predictive early biomarker of acute kidney injury after pediatric cardiac surgery [65]. Interestingly, only two meprin-expression (N-Heptanoylglycine and Taurocholic acid) and one meprin-deficiency associated metabolites (3-Methoxy-4-hydroxyphenylethyleneglycol sulfate) had changed profiles in both plasma and urine but their variable importance in projection scores were opposites. These patterns must be taken into account in development of diagnostic tools.

Of the annotated metabolites, changes in the levels of 8 plasma metabolites and 23 urinary metabolites 
associated with diabetes in both WT and meprin $\beta \mathrm{KO}$ mice, indicating that they are independent of meprin expression or deficiency. Many of these metabolites were reported to associate with diabetic kidney disease or other diabetes complications in previous studies. These include increased plasma and urinary cortisol levels [62], increased urinary betaine excretion [66], decreased urinary galactonic acid levels [43], and increased urinary hippuric acid levels [67]. Furthermore, changes in the levels of polyphenol metabolites were observed in both WT and meprin $\beta$ null mice, indicating the involvement of gut microbiota in the progression of diabetic complications [68]. Certain changes in the intestinal microbiota have been associated with early kidney disease [69]. There were similar levels of decrease in urinary excretion of pantothenic acid in both WT and meprin $\beta \mathrm{KO}$ mice.

\section{Conclusions}

While the targets impacted by meprin metalloproteases in DN are not fully understood, previous in vitro studies have shown that proteolytic processing by meprins could impact the metabolite milieu of the kidneys. The current metabolomics data lead us to conclude that meprin $\beta$ contributes to the progression of diabetic kidney injury through mediating several pathways, reflective of the diversity of the known kidney meprin substrates. This could explain why meprins are harmful in ischemia/ reperfusion-induced acute kidney injury, yet some meprin isoforms are protective in DN. Additional studies, including genomics and proteomics, are desired to better understand the role that meprins plays in the pathophysiology of diabetic kidney injury.

\section{Additional files}

Additional file 1: Table S1. Differentiating metabolites in plasma at 4 weeks post-STZ for analysis in the positive mode. Table S2. Differentiating metabolites in plasma at 4 weeks post-STZ in the negative mode Table S3. Differentiating metabolites in plasma at 8 weeks post-STZ in the positive mode Table S4. Differentiating metabolites in plasma at 8 weeks post-STZ in the negative mode Table S5. Differentiating metabolites in urine 4 week in positive mode Table S6. Differentiating metabolites in urine at 4 weeks post-STZ in the negative mode Table S7. Differentiating metabolites in urine at 8 weeks post-STZ for analysis in the positive mode Table S8. Differentiating metabolites in urine at 8 week post-STZ for analysis in negative mode. (DOCX $113 \mathrm{~kb}$ )

\footnotetext{
Abbreviations

Ac-SDKP: N-acetyl-seryl-aspartyl-lysyl-proline; BBM: Brush-border membrane; CKD: Chronic kidney disease; DN: Diabetic nephropathy; ECM: Extracellular matrix; ELISA: Enzyme-linked immunosorbent assay; EQ: Equilibration; ESRD: End-stage renal disease; FC: Fold-change; HILIC: Hydrophilic interaction liquid chromatography; IL: Interleukin; KIM-1: Kidney injury molecule 1; MCP1: Monocyte chemoattractant protein-1; NaC: Sodium citrate; NGAL: Neutrophil gelatinase-associated lipocalin; OD: Optic density; OS9: Osteosarcoma amplified - 9; PCA: Principle components analysis; PKA: Protein kinase A; PKC: Protein kinase C; QC: Quality control; SNP: Single nucleotide polymorphisms; STZ: Streptozotocin; T2D: Type 2 diabetes;
}

TCA: Taurocholic acid; UACR: Urinary albumin to creatinine ratio; UPLC-QTOF MS: Ultra performance liquid chromatography-quadrupole time-of flight mass spectrometry; VIP: Variable importance in projection; WT: Wild-type; ßKO: Meprin beta knockout

\section{Acknowledgements}

The authors thank Mr. Steven Hurley and Mr. Theodore Bullock of the Laboratory Animal Resource Unit at North Carolina A\&T State University for support in care of the experimental mice.

\section{Funding}

1. NIH/NIGMS Grant \# SC3GM102049 and \#SC1GM118271 and NIH/ NIMHD Center Award \# U54MD008621 (CFDA 93.307), Sub-Awards \# HU140004 to Elimelda Moige Ongeri;

- Paid for maintenance of mice and supplies for induction of diabetes and biochemical assays for kidney function

- Supported Dr. Ongeri's effort

2. NIH Center Grant \# U24DK097193 to Susan Sumner and NIH/NCATS award \# UL1TR001111 to John Buse of UNC CH;

- Covered the costs of metabolomics analysis - including extended data analysis

3. NIH/NIGMS Grant \# K01GM109320 to Jessica Gooding

- Supported Dr. Gooding's effort

\section{Availability of data and materials}

The targeted proteomics data used to support the findings of this study are included within the article. The metabolomics data was deposited at the following links: http://www.metabolomicsworkbench.org/data/ DRCCMetadata.php?Mode=Project\&ProjectID=PR000409 OR https://bit.ly/ 2C95oe1http://www.metabolomicsworkbench.org/data/DRCCMetadata. php?Mode=Project\&ProjectID=PR0004100R https://bit.ly/2tUReZK

\section{Authors' contributions}

4JG: acquisition of data. Data analysis, interpretation of data and drafting and revising of manuscript; given final approval of the version to be published. LC: acquisition of data. Data analysis, interpretation of data and drafting and revising of manuscript; given final approval of the version to be published. CW: acquisition of data. Data analysis, given final approval of the version to be published. J-M M: acquisition of data. Data analysis, interpretation of data and drafting and revising of manuscript; given final approval of the version to be published. MF: acquisition of data. Data analysis, interpretation of data and drafting and revising of manuscript; given final approval of the version to be published. FA: acquisition of data. Data analysis, interpretation of data and drafting and revising of manuscript; given final approval of the version to be published. ZA: acquisition of data. Data analysis, interpretation of data and drafting and revising of manuscript; given final approval of the version to be published. SM: acquisition of data. Data analysis, interpretation of data and drafting and revising of manuscript; given final approval of the version to be published. SS: Conception and design of study, acquisition of data. Data analysis, interpretation of data and drafting and revising of manuscript; given final approval of the version to be published. EMO: Conception and design of study, performed experiments, acquisition of data. Data analysis, interpretation of data and drafting and revising of manuscript; given final approval of the version to be published

\section{Ethics approval}

The study was approved by the Institutional Animal Care and Use Committee (IACUC) at North Carolina A\&T State University.

\section{Consent for publication}

N/A. This was not a human subject study.

\section{Competing interests}

The authors declare that there is no conflict of interest regarding the publication of this article.

\section{Publisher's Note}

Springer Nature remains neutral with regard to jurisdictional claims in published maps and institutional affiliations. 


\section{Author details}

${ }^{1} \mathrm{NIH}$ Eastern Regional Comprehensive Metabolomics Resource Core, University of North Carolina, Chapel Hill, NC, USA. ${ }^{2}$ Discovery Science \& Technology, RTI International, Research Triangle Park, NC, USA. ${ }^{3}$ Department of Biology, North Carolina A\&T State University, Greensboro, NC 27411, USA. ${ }^{4}$ Nutrition Research Institute, University of North Carolina, Chapel Hill, NC, USA.

Received: 3 January 2019 Accepted: 27 March 2019 Published online: 25 April 2019

\section{References}

1. Beynon RJ, Bond JS. Expression of the Mep-1 gene regulating meprin, a kidney brush border proteinase. Prog Clin Biol Res. 1985;180:185-94.

2. Bond JS, Butler PE, Beynon RJ. Metalloendopeptidases of the mouse kidney brush border: meprin and endopeptidase-24.11. Biomed Biochim Acta. 1986:45(11-12):1515-21.

3. Oneda B, Lods N, Lottaz D, Becker-Pauly C, Stocker W, Pippin J, et al. Metalloprotease meprin beta in rat kidney: glomerular localization and differential expression in glomerulonephritis. PLoS One. 2008;3(5):e2278.

4. Sun Q, Jin HJ, Bond JS. Disruption of the meprin alpha and beta genes in mice alters homeostasis of monocytes and natural killer cells. Exp Hematol. 2009:37(3):346-56.

5. Bond JS, Rojas K, Overhauser J, Zoghbi HY, Jiang W. The structural genes, MEP1A and MEP1B, for the alpha and beta subunits of the metalloendopeptidase meprin map to human chromosomes $6 p$ and $18 q$, respectively. Genomics. 1995;25(1):300-3.

6. Jiang W, Dewald G, Brundage E, Mucher G, Schildhaus HU, Zerres K, et al. Fine mapping of MEP1A, the gene encoding the alpha subunit of the metalloendopeptidase meprin, to human chromosome 6P21. Biochem Biophys Res Commun. 1995;216(2):630-5.

7. Gorbea CM, Marchand P, Jiang W, Copeland NG, Gilbert DJ, Jenkins NA, et al. Cloning, expression, and chromosomal localization of the mouse meprin beta subunit. J Biol Chem. 1993;268(28):21035-43.

8. Mathew R, Futterweit S, Valderrama E, Tarectecan AA, Bylander JE, Bond JS, et al. Meprin-alpha in chronic diabetic nephropathy: interaction with the renin-angiotensin axis. Am J Physiol Renal Physiol. 2005;289(4):F911-21.

9. Red Eagle AR, Hanson RL, Jiang W, Han X, Matters GL, Imperatore G, et al. Meprin beta metalloprotease gene polymorphisms associated with diabetic nephropathy in the Pima Indians. Hum Genet. 2005;118(1):12-22.

10. Takayama J, Takaoka M, Yamamoto S, Nohara A, Ohkita M, Matsumura Y. Actinonin, a meprin inhibitor, protects ischemic acute kidney injury in male but not in female rats. Eur J Pharmacol. 2008;581(1-2):157-63.

11. Bylander J, Li Q, Ramesh G, Zhang B, Reeves WB, Bond JS. Targeted disruption of the meprin metalloproteinase beta gene protects against renal ischemiareperfusion injury in mice. Am J Physiol Renal Physiol. 2008;294(3):F480-90.

12. Conley S, Han J, Hurley S, Ongeri EM. Meprin deficient mice have a more severe form of diabetic nephropathy. FASEB J. 2013;27:702.5.

13. Niyitegeka JM, Bastidas AC, Newman RH, Taylor SS, Ongeri EM. Isoformspecific interactions between meprin metalloproteases and the catalytic subunit of protein kinase a: significance in acute and chronic kidney injury. Am J Physiol Renal Physiol. 2015;308(1):F56-68.

14. Ongeri EM, Anyanwu O, Reeves WB, Bond JS. Villin and actin in the mouse kidney brush-border membrane bind to and are degraded by meprins, an interaction that contributes to injury in ischemia-reperfusion. Am J Physiol Renal Physiol. 2011;301(4):F871-82.

15. Huguenin M, Muller EJ, Trachsel-Rosmann S, Oneda B, Ambort D, Sterchi EE, et al. The metalloprotease meprinbeta processes E-cadherin and weakens intercellular adhesion. PLoS One. 2008;3(5):e2153.

16. Bao J, Yura RE, Matters GL, Bradley SG, Shi P, Tian F, et al. Meprin a impairs epithelial barrier function, enhances monocyte migration, and cleaves the tight junction protein occludin. Am J Physiol Renal Physiol. 2013;305(5):F714-26.

17. George JN, Ongeri EM. Degradation of tight junction proteins in meprin betatransfected kidney cells subjected to hypoxia. Federation of American Societies for Experimental Biology; 2013.

18. Herzog C, Marisiddaiah R, Haun RS, Kaushal GP. Basement membrane protein nidogen-1 is a target of meprin beta in cisplatin nephrotoxicity. Toxicol Lett. 2015;236(2):110-6.

19. Kaushal GP, Walker PD, Shah SV. An old enzyme with a new function: purification and characterization of a distinct matrix-degrading metalloproteinase in rat kidney cortex and its identification as meprin. J Cell Biol. 1994;126(5):1319-27.
20. Walker PD, Kaushal GP, Shah SV. Meprin a, the major matrix degrading enzyme in renal tubules, produces a novel nidogen fragment in vitro and in vivo. Kidney Int. 1998;53(6):1673-80.

21. Boyd $\mathrm{S}$, Newman $\mathrm{R}$, Ongeri E. Protein kinase $\mathrm{C}$ alpha is a target for the meprin B metalloproteinase (690.14). FASEB J. 2014;28(1 Supplement):690.14.

22. Chestukhin A, Muradov K, Litovchick L, Shaltiel S. The cleavage of protein kinase a by the kinase-splitting membranal proteinase is reproduced by meprin beta. J Biol Chem. 1996;271(47):30272-80.

23. Chestukhin A, Litovchick L, Muradov K, Batkin M, Shaltiel S. Unveiling the substrate specificity of meprin beta on the basis of the site in protein kinase a cleaved by the kinase splitting membranal proteinase. J Biol Chem. 1997;272(6):3153-60.

24. Herzog C, Haun RS, Kaushal V, Mayeux PR, Shah SV, Kaushal GP. Meprin a and meprin alpha generate biologically functional IL-1 beta from pro-IL1 beta. Biochem Biophys Res Commun. 2009;379(4):904-8.

25. Herzog C, Kaushal GP, Haun RS. Generation of biologically active interleukin1 beta by meprin B. Cytokine. 2005;31(5):394-403.

26. Keiffer TR, Bond JS. Meprin metalloproteases inactivate interleukin 6. J Biol Chem. 2014;289(11):7580-8.

27. Banerjee $\mathrm{S}$, Bond JS. Prointerleukin-18 is activated by meprin beta in vitro and in vivo in intestinal inflammation. J Biol Chem. 2008;283(46):31371-7.

28. Kumar N, Nakagawa P, Janic B, Romero CA, Worou ME, Monu SR, et al. The anti-inflammatory peptide ac-SDKP is released from thymosin-beta4 by renal meprin-alpha and prolyl oligopeptidase. Am J Physiol Renal Physiol. 2016;310(10):F1026-34.

29. Conley S, Martin B, Ongeri EM. Meprins cleave OS-9 present in mouse kidneys subjected to ischemia reperfusion acute kidney injury. The FASEB Journal. 2013;27:705-707.

30. Cao L, Sedighi R, Boston A, Premadasa L, Pinder J, Crawford GE, Jegede OE, Harrison SH, Newman RH, Ongeri EM. Undiagnosed kidney injury in uninsured and underinsured diabetic African American men and putative role of meprin metalloproteases in diabetic nephropathy. International journal of Nephrology. 2018;6753489:eCollection. https://doi.org/10.1155/ 2018/6753489. https://www.ncbi.nlm.nih.gov/pubmed/29854459.

31. Zhao YY, Chen H, Tian T, Chen DQ, Bai X, Wei F. A pharmaco-metabonomic study on chronic kidney disease and therapeutic effect of ergone by UPLCQTOF/HDMS. PLoS One. 2014;9(12):e115467.

32. Liu J, Wang C, Liu F, Lu Y, Cheng J. Metabonomics revealed xanthine oxidase-induced oxidative stress and inflammation in the pathogenesis of diabetic nephropathy. Anal Bioanal Chem. 2015;407(9):2569-79.

33. Sekula P, Goek ON, Quaye L, Barrios C, Levey AS, Romisch-Margl W, et al. A metabolome-wide association study of kidney function and disease in the general population. J Am Soc Nephrol. 2016;27(4):1175-88.

34. Nkuipou-Kenfack E, Duranton F, Gayrard N, Argiles A, Lundin U, Weinberger $\mathrm{KM}$, et al. Assessment of metabolomic and proteomic biomarkers in detection and prognosis of progression of renal function in chronic kidney disease. PLoS One. 2014;9(5):e96955.

35. Pena MJ, Lambers Heerspink HJ, Hellemons ME, Friedrich T, Dallmann G, Lajer M, et al. Urine and plasma metabolites predict the development of diabetic nephropathy in individuals with type 2 diabetes mellitus. Diabet Med. 2014;31(9):1138-47.

36. Breit M, Weinberger KM. Metabolic biomarkers for chronic kidney disease. Arch Biochem Biophys. 2016;589:62-80.

37. Zhang ZH, Wei F, Vaziri ND, Cheng XL, Bai $X$, Lin RC, et al. Metabolomics insights into chronic kidney disease and modulatory effect of rhubarb against tubulointerstitial fibrosis. Sci Rep. 2015;5:14472.

38. Zhao YY, Wang HL, Cheng XL, Wei F, Bai X, Lin RC, et al. Metabolomics analysis reveals the association between lipid abnormalities and oxidative stress, inflammation, fibrosis, and Nrf2 dysfunction in aristolochic acidinduced nephropathy. Sci Rep. 2015;5:12936.

39. Grapov D, Fahrmann J, Hwang J, Poudel A, Jo J, Periwal V, et al. Diabetes associated Metabolomic perturbations in NOD mice. Metabolomics. 2015; 11(2):425-37.

40. Tesch $\mathrm{GH}$, Allen TJ. Rodent models of streptozotocin-induced diabetic nephropathy. Nephrology (Carlton). 2007;12(3):261-6.

41. Gagnebin $Y$, Tonoli D, Lescuyer P, Ponte B, de Seigneux S, Martin PY, et al. Metabolomic analysis of urine samples by UHPLC-QTOF-MS: impact of normalization strategies. Anal Chim Acta. 2017;955:27-35.

42. Warrack BM, Hnatyshyn S, Ott KH, Reily MD, Sanders M, Zhang H, et al. Normalization strategies for metabonomic analysis of urine samples. J Chromatogr B Analyt Technol Biomed Life Sci. 2009; 877(5-6):547-52 
43. van der Kloet FM, Tempels FW, Ismail N, van der Heijden R, Kasper PT, Rojas-Cherto $\mathrm{M}$, et al. Discovery of early-stage biomarkers for diabetic kidney disease using msbased metabolomics (FinnDiane study). Metabolomics. 2012;8(1):109-19.

44. Vogl FC, Mehrl S, Heizinger L, Schlecht I, Zacharias HU, Ellmann L, et al. Evaluation of dilution and normalization strategies to correct for urinary output in HPLC-HRTOFMS metabolomics. Anal Bioanal Chem. 2016:408(29):8483-93.

45. Ruh H, Salonikios T, Fuchser J, Schwartz M, Sticht C, Hochheim C, et al. MALDI imaging MS reveals candidate lipid markers of polycystic kidney disease. J Lipid Res. 2013;54(10):2785-94.

46. Prox J, Arnold P, Becker-Pauly C. Meprin alpha and meprin beta: Procollagen proteinases in health and disease. Matrix Biol. 2015;44(46):7-13.

47. Bylander JE, Ahmed F, Conley SM, Mwiza JM, Ongeri EM. Meprin metalloprotease deficiency associated with higher mortality rates and more severe diabetic kidney injury in mice with STZ-induced type 1 diabetes. J Diabetes Res. 2017;2017:9035038.

48. Herzog C, Haun RS, Shah SV, Kaushal GP. Proteolytic processing and inactivation of CCL2/MCP-1 by meprins. Biochem Biophys Rep. 2016;8:146-50.

49. Banerjee S, Jin G, Bradley SG, Matters GL, Gailey RD, Crisman JM, et al. Balance of meprin $\mathrm{a}$ and $\mathrm{B}$ in mice affects the progression of experimental inflammatory bowel disease. Am J Physiol Gastrointest Liver Physiol. 2011;300(2):G273-82.

50. Jones $\mathrm{H}$, Alpini $\mathrm{G}$, Francis $\mathrm{H}$. Bile acid signaling and biliary functions. Acta Pharm Sin B. 2015;5(2):123-8.

51. Haeusler RA, Astiarraga B, Camastra S, Accili D, Ferrannini E. Human insulin resistance is associated with increased plasma levels of 12alphahydroxylated bile acids. Diabetes. 2013;62(12):4184-91.

52. Zhao YY, Liu J, Cheng XL, Bai X, Lin RC. Urinary metabonomics study on biochemical changes in an experimental model of chronic renal failure by adenine based on UPLC Q-TOF/MS. Clin Chim Acta Int J Clin Chem. 2012; 413(5-6):642-9.

53. Zhao YY. Metabolomics in chronic kidney disease. Clin Chim Acta Int J Clin Chem. 2013:422:59-69.

54. Mishima E, Fukuda S, Mukawa C, Yuri A, Kanemitsu Y, Matsumoto Y, Akiyama Y, Fukuda NN, Tsukamoto H, Asaji K, Shima H, Kikuchi K, Suzuki C, Suzuki T, Tomioka Y, Soga T, Ito S, Abe T. Evaluation of the impact of gut microbiota on uremic solute accumulation by a CE-TOFMS-based metabolomics approach. Kidney Int. 2017;92:634-45.

55. Niwa T, Aoyama I, Takayama F, Tsukushi S, Miyazaki T, Owada A, et al. Urinary indoxyl sulfate is a clinical factor that affects the progression of renal failure. Miner Electrolyte Metab. 1999;25(1-2):118-22.

56. Atoh $\mathrm{K}$, Itoh $\mathrm{H}$, Haneda $\mathrm{M}$. Serum indoxyl sulfate levels in patients with diabetic nephropathy: relation to renal function. Diabetes Res Clin Pract. 2009;83(2):220-6.

57. Liebich HM, Bubeck Jl, Pickert A, Wahl G, Scheiter A. Hippuric acid and 3-carboxy-4-methyl-5-propyl-2-furanpropionic acid in serum and urine. Analytical approaches and clinical relevance in kidney diseases. J Chromatogr. 1990;500:615-27.

58. Rhodes G, Holland ML, Wiesler D, Novotny M, Moore SA, Peterson RG, et al. Excretion of urinary volatile metabolites in response to alloxan induced diabetes of short duration in rats. J Chromatogr. 1982;228:33-42.

59. G-g W, Zhang C, X-h L, Li W. Protective effects of riboflavin on diabetic nephropathy in STZ-induced diabetic rats. Chin J Pathophysiol. 2010;7:039.

60. Mock DM, Wang KS, Kearns GL. The pig is an appropriate model for human biotin catabolism as judged by the urinary metabolite profile of radioisotope-labeled biotin. J Nutr. 1997;127(2):365-9.

61. Schutte A, Ermund A, Becker-Pauly C, Johansson ME, Rodriguez-Pineiro AM, Backhed $F$, et al. Microbial-induced meprin beta cleavage in MUC2 mucin and a functional CFTR channel are required to release anchored small intestinal mucus. Proc Natl Acad Sci U S A. 2014;111(34):12396-401.

62. Chiodini I, Adda G, Scillitani A, Coletti F, Morelli V, Di Lembo S, et al. Cortisol secretion in patients with type 2 diabetes: relationship with chronic complications. Diabetes Care. 2007;30(1):83-8.

63. Meek $J$, Neff NH. The rate of formation of 3-methoxy-4hydroxyphenylethyleneglycol sulfate in brain as an estimate of the rate of formation of norepinephrine. J Pharmacol Exp Ther. 1973;184(3):570-5.

64. Rhee EP, Souza A, Farrell L, Pollak MR, Lewis GD, Steele DJ, et al. Metabolite profiling identifies markers of uremia. J Am Soc Nephrol. 2010;21(6):1041-51.

65. Beger RD, Holland RD, Sun J, Schnackenberg LK, Moore PC, Dent CL, et al. Metabonomics of acute kidney injury in children after cardiac surgery. Pediatr Nephrol. 2008;23(6):977-84.
66. Salek RM, Maguire ML, Bentley E, Rubtsov DV, Hough T, Cheeseman M, et al A metabolomic comparison of urinary changes in type 2 diabetes in mouse, rat, and human. Physiol Genomics. 2007;29(2):99-108.

67. Gilbert RE. Proximal Tubulopathy: prime mover and key therapeutic target in diabetic kidney disease. Diabetes. 2017;66(4):791-800.

68. Bhat Ml, Kapila R. Dietary metabolites derived from gut microbiota: critical modulators of epigenetic changes in mammals. Nutr Rev. 2017;75(5):374-89.

69. Barrios C, Beaumont M, Pallister T, Villar J, Goodrich JK, Clark A, et al. Gutmicrobiota-metabolite Axis in early renal function decline. PLoS One. 2015; 10(8):e0134311.

\section{Ready to submit your research? Choose BMC and benefit from:}

- fast, convenient online submission

- thorough peer review by experienced researchers in your field

- rapid publication on acceptance

- support for research data, including large and complex data types

- gold Open Access which fosters wider collaboration and increased citations

- maximum visibility for your research: over $100 \mathrm{M}$ website views per year

At BMC, research is always in progress.

Learn more biomedcentral.com/submissions 